\title{
LA REHABILITACIÓN DE LA CONDICIÓN DE FUNCIONARIO TRAS CONDENA PENAL. UN ANÁLISIS A LA LUZ DE LOS PRINCIPIOS RECTORES DE LA POTESTAD PUNITIVA ${ }^{1}$
}

\author{
Antoni Gili Pascual \\ Profesor Titular de Derecho penal. \\ Universidad de las Islas Baleares
}

Sumario: I. Introducción II. Pérdida y recuperación de la condición de funcionario. 1. La ejecución de la pena de inhabilitación. Naturaleza. 2. La recuperación de la condición de funcionario tras condena de inhabilitación. Concurso de acceso vs. rehabilitación: dificultades para una fundamentación unitaria de la pena. III. La rehabilitación administrativa tras condena penal 1. Concepto y régimen jurídico. El procedimiento de rehabilitación 2. Fundamento. La rehabilitación administrativa en el sistema de inhabilitación penal IV. Criterios de rehabilitación. Revisión.

Resumen: En relación con las penas de inhabilitación para el ejercicio de la función pública, a menudo la atención del penalista termina en el momento de su imposición. Sin embargo, la fase de ejecución e incluso la fase posterior al cumplimiento de su efecto temporal sigue planteando cuestiones de enorme relevancia, pues estas penas se ven afectadas por disposiciones legales y reglamentarias capaces de acabar perfilando, en el fondo, su propio contenido, como se estudia en este trabajo. Tal es el caso de la normativa que regula hoy la rehabilitación administrativa del funcionario, representada fundamentalmente por el R.D. 2669/1998, de 11 de diciembre. Teniendo en cuenta la unidad de la potestad punitiva del Estado y los principios fundamentales que deben limitarla, como la prohibición de bis in ídem, el presente artículo revisa los criterios actualmente establecidos en dicha regulación. Desentrañar en qué cabe

1 El presente trabajo se ha llevado a cabo en el marco del proyecto Ejecución de penas $y$ medidas de seguridad. Tendencias politico-criminales en las modernas reformas penales, del Ministerio de Economía y Competitividad. 
legítimamente fundamentar — si es que cabe hacerlo- esta posibilidad excepcional de reincorporar al servicio público, por decisión administrativa, a quien fue condenado por sentencia penal firme a quedar excluido definitivamente de ella, constituye en este trabajo el paso previo para poder efectuar después, de forma razonada, dicha revisión crítica. El artículo evidencia que, al igual que ocurre con otras instituciones penales utilitarias de nuestro ordenamiento, como puede ser, salvando las distancias, el caso del indulto, también la rehabilitación de la condición de funcionario requiere una reinterpretación de su fundamento acorde con los principios constitucionales, conforme a la cual adaptar después su regulación y funcionamiento.

Palabras clave: Funcionario público; Rehabilitación; Ejecución de penas.

Abstract: With penalties involving disqualification from public office, legal experts' attention comes to an end once the sentence has been imposed. However, the execution phase and even the phase following compliance with its temporary effects continue to raise issues of huge relevance, since these sentences are affected by legal provisions and regulations which can basically finally shape their actual content, as studied in this paper. This is the case of the legislation that today regulates civil servants' re-admittance to the public administration, mainly represented by Spanish Royal Decree 2669/1998, of December $11^{\text {th }}$. Bearing in mind the unity of the State's ius puniendi and the fundamental principles that must limit the said right, like the non bis in idem principle, this paper reviews the current criteria that regulate these limits. It strives to determine the legitimate grounds, if they do indeed exist, for that exceptional possibility in which someone who has been finally sentenced to perpetual disqualification should be re-admitted to public service under an administrative ruling. This is followed by a reasoned critical review of the situation.

Key words: Civil servant; Re-admittance; Enforcement of ruling.

\section{Introducción}

En alguna ocasión se ha dicho que las penas privativas de derechos en general, y las inhabilitaciones en particular, han sido tradicionalmente las cenicientas tanto del legislador como de los comentaristas ${ }^{2}$. La afirmación, que denuncia la escasa atención que habitualmente se les ha dispensado, merece ser desde luego matizada en lo que al ámbito

2 Manzanares Samaniego, J.L., Las inhabilitaciones para cargo público, en DíEz RipoLLÉs, J.L. (Ed.) La ciencia del Derecho penal ante el nuevo siglo (LH-CEREZo MIR), Tecnos, Madrid, 2002, p. 1096. 
doctrinal se refiere en relación con la última década - aunque no pueda considerarse aún invertida la tendencia-, y ello a la vista de las importantes contribuciones aparecidas tanto en relación con las penas privativas de derechos en general, como en relación con las inhabilitaciones afectantes a la función pública en particular3, penas estas últimas que constituyen el telón de fondo para el objeto de estudio de este trabajo. En cualquier caso, lo que seguramente sí se puede afirmar sin apenas matices es que la atención del penalista en relación con las consecuencias del delito no privativas de libertad a menudo termina con el momento de su imposición, y ello pese a que su seguimiento en la fase de ejecución sigue planteando cuestiones de enorme relevancia ${ }^{4}$. En el caso concreto de las inhabilitaciones para la función pública (inhabilitación absoluta e inhabilitación especial para empleo o cargo de dicha naturaleza -arts. 41 y $42 \mathrm{CP}-$ ), el periodo posterior a la condena, además, interesa no solo desde el punto de vista estadístico o de evaluación de su incidencia ${ }^{5}$, sino

${ }^{3}$ Entre las primeras, por ejemplo, la obra colectiva dir. por FARALdo CABANA, P./PuENTE ABA, L.M., Las penas privativas de derechos y otras alternativas a la privación de libertad, Tirant lo Blanch, Valencia, 2013; entre las segundas, PuEnTE ABA, L.M., La pena de inhabilitación absoluta, Comares, Granada, 2012; VILlaCAMPa Estiarte, C., Las penas de inhabilitación en la Unión Europea: regulación comparada y proceso de armonización, en Las sanciones penales en Europa, Aranzadi, 2009, p. 251 ss.; MAPELli CAFFARENA, B., La pena de inhabilitación absoluta ¿es necesaria?, CPC, n. ${ }^{\circ}$ 108, 2012; VALEIJE ÁlvAREZ, I., La reforma del régimen de la accesoriedad penal. Especial referencia al Proyecto de Ley Orgánica de Reforma del Código Penal de 2007, en Álvarez García, F.J. (Dir.), La adecuación del Derecho penal español al ordenamiento de la Unión Europea. La Política criminal europea, Tirant lo Blanch, Valencia, 2009

${ }^{4}$ Como lamentaba hace unos años Valeije, no «se registran especiales esfuerzos por componer un tratamiento integral de ejecución de esta clase de penas (ref. a las privativas de derechos) que deberían alcanzar a todos los marcos penales en que esa privación puede producirse y que resulte en cierto modo similar al previsto para la pena privativa de libertad (el sistema de ejecución progresivo)»(VALEIJE ÁlVAREZ, I., La reforma ..., cit., p. 190).

${ }^{5}$ En este primer sentido, no puede dejar de mencionarse que la ejecución de las inhabilitaciones experimenta en muchas ocasiones una relajación de facto que debería constituir por sí sola un importante foco de atención, pues debilita la propia vigencia de las normas que las prevén, y seguramente retroalimenta una situación en la que la revisión a fondo de estas consecuencias jurídicas, tan necesaria (VILlacampa Estiarte, C., Las penas de inhabilitación , cit., p. 291 ss.; VALEIJE Álvarez, I., La reforma ..., cit., p. 213), se percibe en cambio como una exigencia no acuciante, y ello pese a que estas penas arrastran aún tintes infamantes propios de su origen histórico, decimonónico, a la vez que presentan deficiencias en relación con principios básicos limitadores de la potestad punitiva del Estado, como los de igualdad, legalidad o proporcionalidad (puede verse, VALEIJE ÁLVAREZ, I., La reforma ..., cit., p. 193 ss; DomínguEz IzouiERDo, E.M., Cuando la pena accesoria de inhabilitación especial requiere relación directa con el delito cometido: el contenido del art. 56.1.3 del Código penal, CPC, n. ${ }^{\circ}$ 112, 2014, p. 139, 162; MaPelli CafFarena, B., La pena de inhabilitación ..., cit., p. 28; Puente Aba, L.M., en Faraldo Cabana, P./Puente Aba, L.M., Las penas privativas de derechos ..., cit., p. 60, 85; SÁnCHEZ MelgaR, J., La pena de inhabilitación: constitucionalidad, contenido y problemas, CDJ, n. ${ }^{\circ} 15,2003$, p. 354). En efecto, y como se ha observado en alguna ocasión, una de las razones que seguramente explican que esta clase de penas se hayan podido mantener prácticamente inalteradas es su diluida aplicación práctica, debida entre otros motivos a la descoordinación de la propia Administración de Justicia en la ejecución de los fallos condenatorios y a la falta de una 
también normativo, pues estas penas se ven afectadas por disposiciones capaces de acabar perfilando, en el fondo, su propio contenido, como se verá en este trabajo. En efecto, en el caso de las inhabilitaciones relacionadas con el empleo público, en concreto, no ya la fase estricta de su ejecución, sino incluso la fase posterior a su cumplimiento (o extinción por otras causas $-v$. g. por indulto o prescripción de la pena-) se revela de enorme trascendencia, pues diversa normativa extrapenal puede acabar modulando sendos efectos de estas penas, esto es, tanto el de carácter temporal (la imposibilidad para obtener los empleos o cargos públicos correspondientes durante un periodo de tiempo determinado) como el de carácter definitivo (la pérdida del empleo o cargo público con carácter, dice hoy la Ley ${ }^{6}$, definitivo):

a) Por una parte, porque la posibilidad de acceder por primera vez a la función pública o de reeditar el acceso que ya se obtuvo en otro momento (y que la pena vetó por un periodo temporal determinado), si se pretende alcanzar por la vía ordinaria del concurso u oposición (o sistema de acceso general) correspondiente puede verse seriamente matizada por prescripciones administrativas diversas que acabarán perfilando en la práctica los contornos reales de la privación de derechos impuesta. Puede ocurrir, así, que el acceso al cuerpo al que se pertenecía, o al que se quiere pertenecer ex novo, tenga previstas limitaciones de edad que le resulten al condenado de imposible cumplimiento una vez extinguido el efecto temporal de la pena. O que, en otro ejemplo, las disposiciones normativas aplicables a los concursos pertinentes impongan requisitos suplementarios que resulten incumplidos precisamente a consecuencia de la condena, como puede ser el de carecer de antecedentes penales ${ }^{7}$, requisito que prolongará y, en ese sentido, amplificará, por vía administrativa, los efectos gravosos de la pena.

b) Pero por otra - y este será el objeto de atención en este trabajoexisten previsiones legales y reglamentarias a través de las que se ve directamente concernido el primero y principal de los dos efectos que poseen las penas de inhabilitación: la pérdida definitiva de la condición pública. Desde que la Ley 13/1996, de medidas fiscales, administrativas y del orden social activara la posibilidad

información fluida entre las distintas Administraciones. En este sentido señala MAPELLI (La pena de inhabilitación ..., cit., p. 7) que ello convierte en muchas ocasiones a la inhabilitación en una pena puramente nominal, sin ejecución de oficio, de la que tan solo puede diligenciarse su efectivo cumplimiento si alguien lo denuncia.

6 No lo decía expresamente, en cambio, el Código derogado (arts. 35 y 36 ACP), si bien la dicción legal era igualmente interpretada en ese sentido.

7 Otra institución tradicionalmente olvidada (así, LARRAuri PiJOAN, E./JACOBS, J.B., Reinserción laboral y antecedentes penales, RECPC, 13-09, 2011, p. 4 y n. 9) pero de innegable - y creciente- relevancia. 
de que los órganos de gobierno de las Administraciones Públicas concediesen la rehabilitación, a petición del interesado, de quien hubiera sido condenado a la pena principal o accesoria de inhabilitación, dicha posibilidad se ha mantenido, de forma más o menos silenciosa (no hay estadísticas públicas sobre su concesión) en nuestro ordenamiento, apareciendo actualmente recogida en el art. 68.2 del Estatuto Básico del Empleado Público y regulada, fundamentalmente, por el Real Decreto 2669/1998, de 11 de diciembre.

La jurisprudencia contencioso-administrativa, a la que debe necesariamente atenderse al ser ésta la llamada a ocuparse del control jurisdiccional de las decisiones administrativas en este campo, se ha afanado, como se verá, en intentar independizar esta institución rehabilitadora de la naturaleza penal del presupuesto del que trae causa, parapetándose para ello en la naturaleza estrictamente administrativa de la cuestión, que se ha intentado ceñir a una mera manifestación más de las facultades para configurar el régimen estatutario de los funcionarios públicos. Y tal vez deba considerarse así. Pero lo cierto es que ese parapeto formal no puede ocultar que materialmente, se quiera o no, a través del procedimiento de rehabilitación viene a mutarse la naturaleza de la pena, que, en ese concreto aspecto y para el caso concreto, con todos los matices que se quiera, pasa a transformarse de inhabilitación en pena de suspensión.

Los aspectos de este proceso que pueden resultar llamativos desde la óptica penal y desde la propia consideración a la unidad de la potestad punitiva del Estado no terminan ahí. Una aproximación inicial a la aplicación jurisprudencial de esta normativa revela, en primera instancia, cuando menos una falta de previsibilidad ex ante, de certeza, acerca del sentido de la decisión. En la jurisprudencia reciente de la Sala Contencioso-Administrativo del Tribunal Supremo conviven, de entrada, resoluciones favorables a la rehabilitación de penas graves (v. g., STS de 16 de septiembre de 2013: inhabilitación absoluta, por delito de malversación del art. $432 \mathrm{CP}$ ) con resoluciones denegatorias en relación con penas menos graves (v. g., STS de 14 de octubre de 2010: un año de inhabilitación especial, por falsedad en documento oficial). Descendiendo a los fundamentos jurídicos de las resoluciones sobre la materia, por otra parte, puede encontrarse la toma en consideración de las más variadas y a priori desconcertantes circunstancias, como la existencia en el expediente de un escrito firmado por un elevado número de compañeros expresando su solidaridad al recurrente (STS de 14 de julio de 2004) o el hecho de que la sentencia condenatoria dictada en su momento fuese de conformidad (STS de 10 de julio de 2017). Pero al margen de aspectos que pueden entenderse tomados en consideración en resoluciones aisladas, resulta también chocante que en los criterios generales que más a menudo se repiten se aprecie con frecuencia una doble valoración respecto de los hechos que motivaron la condena. En este sentido, para denegar la reha- 
bilitación se valora frecuentemente, por ejemplo, la propia naturaleza del bien jurídico afectado o el carácter doloso del hecho, cuestiones que obviamente ya se tuvieron en cuenta para imponer la pena que se impuso y que ahora, en el procedimiento de rehabilitación, vuelven a considerarse para, en definitiva, agravar (no revertir) sus efectos. La situación tampoco puede extrañar cuando el propio art. 6.2 R.D. 2669/1998, al enunciar los criterios que orientativamente deben considerarse en este procedimiento viene a incurrir en esa doble valoración, lo que merece seguramente alguna reflexión desde la prohibición de bis in idem.

Toda esta, aparentemente desordenada, situación, puede tener $-\mathrm{O}$ no- una justificación plausible. Este artículo se acerca a esta problemática tratando de precisar el encaje de la institución en el sistema. Desentrañar en qué cabe legítimamente fundamentar, si es que cabe hacerlo, esta posibilidad excepcional de reincorporar al servicio público, por decisión administrativa, a quien fue condenado por sentencia penal firme a quedar excluido definitivamente de ella (III.2) constituye el paso previo para poder valorar después, de forma razonada, los criterios que para esa reincorporación maneja hoy nuestro Derecho positivo (infra IV). Antes debe exponerse, no obstante, la mecánica que rige actualmente tanto la pérdida como la recuperación de la condición de funcionario tras condena penal de inhabilitación (II), así como las líneas básicas de funcionamiento del propio procedimiento de rehabilitación administrativa y sus características esenciales, tal y como aparece actualmente regulado en nuestro Derecho (III.1).

\section{Pérdida y recuperación de la condición de funcionario}

\section{La ejecución de la pena de inhabilitación. Naturaleza}

La condena firme a pena de inhabilitación, sea absoluta o especial, principal o accesoria, comporta como primero de sus dos efectos la pérdida definitiva de la condición de funcionario. Así lo recoge hoy el art. 63 del Real Decreto Legislativo 5/2015, de 30 de octubre, por el que se aprueba el texto refundido de la Ley del Estatuto Básico del Empleado Público, precisando el art. 66 de ese mismo cuerpo legal, en consonancia

8 Con anterioridad, la Ley de Funcionarios Civiles del Estado se refería como causa de pérdida de la condición de funcionario a la «pena principal o accesoria de inhabilitación absoluta o especial para cargo público» (art. 37.1.d), disposición que se modificaría en 1996 para, por un lado, pasar a referirse la citada letra (d) solo a la inhabilitación absoluta, y por otro añadir un aptdo. segundo al art. 37 que con más precisión especificaría que la pérdida de la condición de funcionario se produciría también «cuando reca[yese] pena principal o accesoria de inhabilitación especial en el ejercicio de las funciones correspondientes al puesto de trabajo o empleo relacionado con esta condición, especificado en la sentencia». 
con lo dispuesto en el Código penal, que «la pena principal o accesoria de inhabilitación absoluta cuando hubiere adquirido firmeza la sentencia que la imponga produce la pérdida de la condición de funcionario respecto a todos los empleos o cargos que tuviere», mientras que «la pena principal o accesoria de inhabilitación especial cuando hubiere adquirido firmeza la sentencia que la imponga produce la pérdida de la condición de funcionario respecto de aquellos empleos o cargos especificados en la sentencia» ${ }^{9}$.

La declaración de firmeza de la sentencia es pues, y como no puede ser de otro modo, requisito necesario para la pérdida de la condición de funcionario, de modo que si se acordase una ejecución provisional de la sentencia dictada en primera instancia en la que la pena de inhabilitación apareciera como accesoria a otra privativa de libertad podría acordarse ciertamente la suspensión de funciones con ocasión de la tramitación del procedimiento judicial, como establece el art. 90.4 EBEP ${ }^{10}$, pero siempre aguardando a la declaración de firmeza para poder acordar la pérdida de la condición de funcionario público del condenado ${ }^{11}$.

9 Ello ha de comportar que en el caso de que un mismo funcionario pertenezca a varios Cuerpos y en la sentencia no se reflejen todos, pueda mantener su condición funcionarial respecto a aquellos que no aparezcan expresamente recogidos en la resolución judicial, del mismo modo en que podría participar el condenado a esta pena en nuevos procesos selectivos para Cuerpos o Escalas distintas de aquella para la que fue inhabilitado (Pérez Gómez, J.M., en Palomar Olmeda, A./Sempere Navarro, A.V. (Dirs.), Comentario a la Ley 7/2007, de 12 de abril, del Estatuto Básico del Empleado Público, Aranzadi, $2 .^{a}$ ed., 2009, p. 714). Debe tenerse presente que la condición pública puede ostentarse por conceptos distintos, existiendo diferentes situaciones administrativas que permiten compatibilizarlos, al igual que existe la posibilidad de conjugar un empleo público con un cargo político que simplemente no suponga dedicación exclusiva, lo que ha de permitir una privación selectiva (véase, BAucells Lladós, J., en CóRdoba RodA, J. /GARCIA ARÁN, M., Comentarios al Código penal. Parte General. Marcial Pons, Madrid, 2011, p. 467; PuEnTE ABa, L.M., en Faraldo Cabana, P./Puente ABa, L.M., Las penas privativas de derechos y otras alternativas a la privación de libertad, Tirant lo Blanch, Valencia, 2013, p. 85).

En cualquier caso, la privación no puede serlo solo de parcelas o facetas de un mismo empleo. Ilustrativa en este sentido resulta la SAN de 25 enero 2012 (Sala de lo Contencioso-Administrativo, Secc. 5. ${ }^{a}$, rec. 1536/2009), indicando que la pérdida se ha de producir, en las condenas a penas de inhabilitación especial, respecto del Cuerpo en el que se desempeñan las funciones que se encuentran conectadas a la comisión del delito, no en otros Cuerpos de los que también pueda formar parte el empleado público, pero que en ningún caso se trata de la «mera pérdida de destino o del puesto de trabajo» con simple limitación para ocupar los de la misma clase (en ese caso, extranjería) durante el tiempo de la condena, pues ello desvirtuaría la pena, conllevando efectos incluso más beneficiosos que la suspensión de empleo o cargo público.

10 Pérez Gómez, J.M., en Palomar Olmeda, A./Sempere Navarro, A.V. (Dirs.), Comentario a la Ley 7/2007, de 12 de abril, del Estatuto Básico del Empleado Público, cit., p. 713.

11 Por otra parte, la jurisprudencia de la Sala Contencioso-Administrativo tiene también declarado que en los casos en que haya un procedimiento disciplinario abierto por los mismos hechos ello no supone que la Administración deba esperar a que éste finalice para decretar la pérdida de la condición de funcionario si la sentencia penal que impuso la inhabilitación adquirió firmeza. Así, se lee en la STS, Sala Cont.-Adm., Secc. 7. a , de 26 de diciembre de 2012 (Roj: 8788/2012), que «la incoación y tramitación de un expediente 
Pero, más allá de esa elemental exigencia de firmeza, no se necesitan ulteriores requisitos, de modo que la privación se hará efectiva a partir de la remisión de testimonio de la sentencia al organismo público del que dependa el condenado, a través del acto administrativo correspondiente por parte de las autoridades competentes en materia de personal. En este sentido, la jurisprudencia ha sido constante a la hora de señalar que se trata de una consecuencia que opera automáticamente, tan pronto como se produce el hecho determinante establecido en la Ley, esto es, la sanción penal (v. g. STS de 16 de enero de 2012 o STS de 1 junio de 2009), no requiriéndose, así, de especial procedimiento administrativo, ni, en particular, del trámite de audiencia, pues la Administración se limita aquí - ha reiterado el Alto Tribunal- a constatar el presupuesto normativo y a aplicar la consecuencia querida por la Ley (v. g., SSTS de 24 de junio de 2010, 21 de diciembre de 2000 o 18 de mayo de 1998) mediante lo que no es sino un acto debido, que debe practicarse de oficio una vez recibida la notificación de la sentencia.

Naturalmente, para poder afirmar ese carácter meramente declarativo de la resolución administrativa por la que se establece la pérdida de la condición funcionarial, sin necesidad siquiera de audiencia, la jurisprudencia ha tenido que negar su naturaleza sancionadora, negación que le ha permitido también esquivar, al menos formalmente, la infracción del principio non bis in idem, con el que dicha jurisprudencia no encuentra contradicción alguna (v. g., STS de 16 de enero de 2012). Para el Tribunal Supremo — en posición, por lo demás, sostenida de forma ininterrumpida desde la previsión del artículo 37.1.d) de la Ley de Funcionarios Civiles del Estado de 1964-, la pérdida de la condición de funcionario a causa de la pena de inhabilitación absoluta o especial para cargo público no constituye una sanción disciplinaria (v. g., STS de 24 de junio de 2010), sino que responde simplemente al ejercicio de las facultades administrativas en materia de personal y, concretamente, de las relativas a la regulación estatutaria de la relación funcionarial, limitándose a trasladar a este ámbito los efectos de una sentencia condenatoria que, en este sentido, operaría a modo de condición resolutoria, en coherencia con el requisito de aptitud exigido para ser funcionario (SSTS de 26 de diciembre de 2012; 10 de abril de 2006; 13 de enero de 2004; 24 de enero de 2004; 3 de marzo de 1997), requisito cuya «ausencia sobrevenida» (STS de 24 de junio de 2010) simplemente se estaría constatando. La pena de inhabilitación ostentaría, pues, dos vertientes,

disciplinario como consecuencia de los mismos hechos objeto de la causa penal que finalizó con la condena del recurrente antes referida, no imposibilitaba ni suponía que la Administración tuviera que esperar a que aquél finalizara para dar debido cumplimiento a lo previsto en el art. 63.e) en relación con el 66 EBEP, resultando pues conforme a derecho la pérdida de la condición de Policía del CNP del recurrente acordada tras conocerse que había adquirido firmeza la sentencia que le impuso la pena de inhabilitación absoluta por tiempo de seis años». 
la de sanción impuesta en un proceso penal por el órgano jurisdiccional correspondiente y, simultáneamente, la de «presupuesto habilitante» de los órganos administrativos con competencia en materia de personal para dictar la correspondiente resolución que declare la extinción funcionarial (v. g., SSTS de 15 de noviembre de 2011; 13 de febrero de 2006 o 5 de octubre de 2004).

\section{La recuperación de la condición de funcionario tras condena de inhabilitación. Concurso de acceso vs. Rehabilitación: dificultades para una fundamentación unitaria de la pena}

Aunque el Código penal vigente adjetiva expresamente las privaciones de derechos contenidas en los arts. 41 y 42 CP (inhabilitación absoluta e inhabilitación especial para cargo público) como «definitivas» - cosa que no habían hecho con anterioridad los homólogos arts. 35 y 36 del Código derogado ${ }^{12}$-, la condición de funcionario perdida definitivamente puede recuperarse después, tras la extinción de la responsabilidad penal, por dos procedimientos distintos. El primero, que la jurisprudencia ha calificado en alguna ocasión como vía «ordinaria» (v. g., en STS de 5 de julio 2016), es la participación, de nuevo, en los correspondientes procesos selectivos que se convoquen para, en caso de superarlos, ser nombrado nuevamente funcionario. El segundo es la rehabilitación de la que se ocupa este trabajo y que tiene, según jurisprudencia unánime, carácter extraordinario (amén de señalarlo así el art. 68.2 EBEP, que se refiere a su concesión con carácter excepcional). A estas dos vías podría añadirse todavía, aunque a título prácticamente anecdótico, alguna otra circunstancia anómala que, pese a no estar específicamente establecida para recuperar la condición de funcionario, en algún caso ha podido conducir a dicho resultado ${ }^{13}$. Pero detengámonos en las dos inicialmente indicadas:

12 Si bien la interpretación que les atribuía igualmente ese carácter definitivo era la mayoritaria en doctrina, toda vez que la expresión «durante el tiempo de la condena» se usaba solo respecto de la incapacidad para obtener los cargos u honores, no respecto de su privación, que se entendía por ello, a contrario, definitiva (Cfr. BAUCELLS Lladós, J., en Córdoba Roda, J./Garcia Arán, M., Comentarios al Código penal. Parte General. Marcial Pons, Madrid, 2011, p. 463).

13 Es el caso de la aplicación de la retroactividad favorable ante una sucesión normativa, que en algún supuesto puntual ha permitido restaurar la condición pública pese a la condena firme de inhabilitación. Así ocurrió, p. ej., en el supuesto que da vida a la STS (Sala de lo Penal) núm. 1327/1998, de 10 de nov. (RJ 1998/8585). En él, declarada por Auto de la A. Prov. Logroño de 7 de octubre de 1996 la firmeza de la sentencia que condenaba a la acusada, entre otras, a la pena de inhabilitación especial por un delito de prostitución del antiguo art. 452 bis b) ACP, ésta fue revisada para sustituirla por la aplicación del art. 187 del nuevo Código, al preferir la acusada que le fuese «levantada la pena de inhabilitación especial». 
a) La privación del empleo o cargo se mantiene durante el tiempo de la condena, sin perjuicio de que, tras extinguirse aquélla, el condenado pueda optar de nuevo a su ocupación pública —o pueda hacerlo por primera vez, si no la tuvo nunca- mediante el sistema legalmente previsto (oposición, concurso de méritos, elección, etc.) ${ }^{14}$. Esta posibilidad de reingresar en la función pública, si bien pudo generar algunas dudas en su momento, resulta hoy pacífica tanto en el sentir jurisprudencial como en el doctrinal ${ }^{15}$, sin que merezca por ello la pena detenerse en este punto. Sí conviene a mi juicio, en cambio, hacerlo en las dos puntualizaciones siguientes:

Primera, que aunque lo anterior es efectivamente así sobre el papel, no cabe desconocer que el acceso a la ocupación pública puede prever ulteriores exigencias que dificultarán (y hasta imposibilitarán en algún caso) el reingreso. De entrada, y pese a que el art. 56.1.d) EBEP no lo exija expresamente ${ }^{16}$, la normativa sectorial o bien las correspondientes convocatorias de los distintos procesos selectivos podrán exigir, para par-

14 A juicio de MAPELli la incompatibilidad de la condena a pena de inhabilitación se produce únicamente en relación con la toma de posesión del empleo o cargo, de modo que, dado que los procesos de selección son en ocasiones largos, la inhabilitación no impediría que un condenado pudiese firmar unas pruebas e incluso concurrir a ellas cuando está cercano a completar el cumplimiento y presuma que el retraso de las mismas le va a permitir llegar a la toma de posesión con la pena cumplida (MAPELLI CAFFARENA, B., CPC n. ${ }^{\circ} 108,2012$, p. 25). No obstante, hay que contar con que la regulación de los propios procesos selectivos impedirá presentarse, y que ya a nivel legal el propio EBEP (art. 56) exige para participar en ellos «no hallarse en inhabilitación absoluta o especial para empleos o cargos públicos por resolución judicial».

15 Boldova Pasamar, M.A., en Gracia Martín, L. (coord.), Lecciones de consecuencias jurídicas del delito, 5. ${ }^{\mathrm{a}}$ ed., Tirant lo Blanch, Valencia, 2016, p. 65; Mapelli CAFFarena, B., Las consecuencias jurídicas del delito, 5. ${ }^{a}$ ed., Civitas, Madrid, 2011, p. 262; ARRIBAS LóPEZ, E., Sobre la rehabilitación de los funcionarios inhabilitados, Actualidad Administrativa, n. ${ }^{\circ}$ 2, febr. 2017, p. 4; del mismo, Consecuencias administrativas derivadas del cumplimiento de penas privativas de derechos por funcionarios públicos, La Ley, 2008-4, p. 1600; Pérez Gómez, J.M., en Palomar Olmeda, A./Sempere Navarro, A.V. (Dirs.), Comentario a la Ley 7/2007, de 12 de abril, del Estatuto Básico del Empleado Público, Aranzadi, 2. ${ }^{a}$ ed., 2009, p. 714; Puente Aba, L.M., en Faraldo Cabana, P./Puente Aba, L.M., (Dirs.), Las penas privativas de derechos ..., cit., p. 56 y 86; Baucells Lladós, J., en CóRdoba RodA, J./Garcia ARÁn, M., Comentarios ..., cit., p. 464.

16 Como requisito general para participar en los procesos selectivos el art. $56.1 \mathrm{~d}$ ) EBEP señala únicamente la necesidad de «no haber sido separado mediante expediente disciplinario del servicio de cualquiera de las Administraciones Públicas o de los órganos constitucionales o estatutarios de las Comunidades Autónomas, ni hallarse en inhabilitación absoluta o especial para empleos o cargos públicos por resolución judicial, para el acceso al cuerpo o escala de funcionario, o para ejercer funciones similares a las que desempeñaban en el caso del personal laboral, en el que hubiese sido separado o inhabilitado (...)». Debe tenerse presente, asimismo, que en relación con el personal eventual el propio EBEP señala que les será aplicable el régimen general de los funcionarios de carrera (arts. 10.5), al igual que ocurre con el personal funcionario interino (art. 12.5 EBEP y art. 27.2 del Reglamento General de Ingreso de Personal de la Administración, Provisión de Puestos y Promoción —-Real Decreto 364/1995, de 10 de marzo-), por lo que tampoco podrán estar incursos en inhabilitación penal para su acceso. 
ticipar en ellos, la ausencia de antecedentes penales ${ }^{17}$, lo que, al requerir su cancelación del transcurso de cierto periodo de tiempo computado desde la extinción de la pena (art. 136. 1 y 2 CP), supondrá de facto la prolongación por normas administrativas del efecto de separación del servicio impuesto como inhabilitación penal. Ello sin contar que, en relación con determinadas profesiones - singularmente en el caso de funcionarios policiales o militares-, aun alcanzada la cancelación de los antecedentes penales, el reingreso será sencillamente inviable por razón de la edad requerida para ello ${ }^{18}$. La combinación normativa puede hacer, por tanto, que la privación definitiva se convierta en una privación perpetua, irreversible. Y todo ello, en fin, sin contar que una adecuada dosis de realismo convierte muchas veces la posibilidad de un regreso tras repetir las pruebas superadas muchos años antes en poco menos que una ironía ${ }^{19}$.

Segunda, que esta conversión del carácter definitivo en perpetuo no puede, de todos modos, sorprender. Pues amén de que tales efectos permanentes, tan combatidos respecto de penas de mayor renombre, se dan en la práctica en otros supuestos del Código ${ }^{20}$, tampoco cabe desconocer que en relación, en concreto, con la incapacidad para ser empleado público, ésta durará toda la vida en el caso de quien haya sido disciplinariamente separado del servicio ${ }^{21}$, pues dicha sanción no tiene previsto

17 Sobre los empleos, no solo públicos, que exigen carecer de antecedentes penales puede verse LARRAURI PIJOAN, E./JACOBS, J.B., Reinserción laboral y antecedentes penales, RECPC 13-09 (2011), así como la actualización de este trabajo: LARRAURI PIJOAN, E., ¿En qué empleos se exigen los antecedentes penales?, RECPC 15-r3 (2013). Cfr., también, Puente ABA, L.M., La pena de inhabilitación absoluta, cit., p. 128 ss., proponiendo pautas restrictivas a la extensión de los efectos de la condena más allá de la fecha de su extinción que supone la toma en consideración de los antecedentes, tales como su utilización con carácter excepcional, únicamente para el acceso a determinadas profesiones o funciones especialmente importantes.

18 Esta situación contiene, además, una sustancial desigualdad con respecto a otras privaciones profesionales. Mientras que en estas no es posible privar al sujeto que ha cometido el delito de su profesión, entendida como habilitación de un título para su ejercicio, tal privación se produce inexcusablemente en el ámbito de la función pública: SÁNCHEZ MELgaR, J., La pena de inhabilitación ..., cit., p. 354.

19 Como apuntara Manzanares Samaniego, J.L., Las inhabilitaciones ..., cit., p. 1095.

20 Así, respecto de la privación de la patria potestad, que puede tener efectos a perpetuidad, cuando menos en los supuestos de patria potestad prorrogada ( $v i d$. VILLACAMPA Estiarte, C., Penas accesorias, en Álvarez García, J./González Cussac, J.L., Comentarios a la reforma penal de 2010, Tirant lo Blanch, Valencia, 2010, p. 115 s.).

21 Pérez Gómez, J.M., en Palomar Olmeda, A./Sempere Navarro, A.V. (Dirs.), Comentarios a la Ley 7/2007, del Estatuto Básico del Empleado Público, 2. ${ }^{a}$ ed., Aranzadi, 2009, p. 611; Luque Parra, en Del Rey Guanter, S. (Dir.) Comentarios al Estatuto Básico del Empleado Público, La Ley, Madrid, 2008, p. 727; Villacampa Estiarte, C., Las penas de inhabilitación en la Unión Europea ..., cit., p. 294; MANZANA LaGUARDA, R., Derechos y deberes de los funcionarios públicos, Tirant lo Blanch, Valencia, 2006, p. 609; QUINTANAR LÓPEZ, T., La potestad disciplinaria de las administraciones sobre los empleados públicos, Documentación Administrativa, n. ${ }^{\circ}$ 282-283, 2009, p. 347. Hay que tener en cuenta, en este sentido, que si bien la inhabilitación no ha de impedir el reingreso tras el cumplimiento, éste no será posible si fue acompañada de sanción disciplinaria de separación, que la 
procedimiento de rehabilitación ${ }^{22}$. Ello si bien, y para terminar de completar un panorama plagado de desigualdades difícilmente explicables con un hilo argumental común, aquella situación no se da respecto de

jurisprudencia permite simultanear sin que ello encierre necesariamente infracción de la prohibición de bis in ídem (Palomar Olmeda, A., Derecho de la Función pública, Dykinson, Madrid, 8. ${ }^{\mathrm{a}}$ ed., 2009, p. 268).

$22 \mathrm{Y}$ es que al aludir a los requisitos para poder participar en los procesos selectivos el art. 56.1 d) EBEP se refiere, congruentemente, a la necesidad, sin matices, de «no haber sido separado mediante expediente disciplinario del servicio», mientras que alude a la circunstancia de no hallarse, en el momento en cuestión, «en inhabilitación absoluta o especial para empleos o cargos públicos por resolución judicial».

Este carácter irreversible de la más grave de las sanciones disciplinarias, que contrasta con la reversibilidad de la condena penal a inhabilitación, ha intentado justificarse en doctrina apuntando que los fines de reeducación y reinserción social a los que deben orientarse las penas no resultan en realidad de obligada persecución para las sanciones disciplinarias ni para el resto de sanciones administrativas (vid., MARINA JALVO, B., El régimen disciplinario de los funcionarios públicos, Lex Nova, Valladolid, 1. ${ }^{\mathrm{a}}$ ed., 1999, 361 -si bien la autora tildaba de incomprensible la disparidad: op. cit., p. 365-). Al respecto, y al margen de que la previsión del art. 25.2 CE se refiera, strictu senso, a las penas privativas de libertad y medidas de seguridad (con lo que el elemento diferencial advertido no operaría como tal en relación con las penas privativas de derechos), el contraargumento de fondo para protestar frente a la mayor gravedad de la sanción disciplinaria sigue siendo otro: escudarse formalmente en su naturaleza distinta. En realidad, como ya señalara Octavio de Toledo, la separación del servicio es uno de los más nítidos ejemplos de cómo la evolución del Derecho disciplinario, su aproximación al Derecho penal, no ha acabado y todavía presenta rasgos primitivos, a cuya desaparición debería estar abocado (Octavio DE Toledo y Ubieto, E., La prevaricación del funcionario público, Civitas, Madrid, 1980, p. 281).

También jurisprudencialmente se ha intentado apuntalar la diferencia con el citado y con otros argumentos, que sin embargo no pueden convencer. Para la STSJ Madrid, de 29 de octubre de 2003 (cit. por LuQue Parra, en Del Rey Guanter, S. (Dir.) Comentarios ..., cit., p. 728 s., y tenida por justificación suficiente por este autor), que el legislador no haya previsto la rehabilitación para la sanción de separación disciplinaria del servicio encontraría su fundamento en los siguientes argumentos: $« 1 .^{\circ}$ ) En la temporalidad de la inhabilitación absoluta o especial, como pena principal o accesoria de un proceso penal, frente a la perdurabilidad de la sanción disciplinaria de separación del servicio, (....). 2. ${ }^{\circ}$ ) En que los hechos por los que se le separa a un funcionario en un procedimiento disciplinario son hechos cometidos con una relación especialmente vinculada con el desempeño del puesto, relación que deriva de la particular sujeción del funcionario con la Administración de forma que ésta entiende desde el momento en que impone esta sanción -la más grave de todas-, que no es conveniente reiniciar tal relación en ningún momento posterior. Esa especial vinculación del hecho delictivo con el desempeño del cargo funcionarial no se da automáticamente en el supuesto de los delitos (...). 3..$\left.^{\circ}\right)$ En que además el Derecho penal tiene un reconocido fin rehabilitador del delincuente que no se extiende a las sanciones disciplinarias donde predomina la ejemplaridad hacia el propio funcionario y hacia el resto de compañeros». Como puede verse, el primero de los argumentos consiste en dar por supuesto precisamente lo que se quiere justificar. El segundo, se desentiende del propio fundamento de la inhabilitación que, a mi juicio, solo puede encontrar una legitimación atendible desde los patrones del Derecho penal actual cuando se requiere la relación con el hecho cometido (siendo criticables, en otros términos, los supuestos en los que se aplica prescindiendo de dicha relación). El último de ellos es el ya comentado, que escudándose en la independencia de la sanción administrativa, decide que la ejemplaridad es incompatible con la rehabilitación. 
determinadas profesiones públicas, que sí permiten la rehabilitación de la sanción disciplinaria, como ocurre singularmente con las relacionadas con la Administración de Justicia ${ }^{23}$.

b) La rehabilitación es, justamente, la segunda de las dos vías actualmente establecidas para poder recuperar, aquel que ya la ostentó (no quien nunca la obtuvo), la condición de funcionario de la que le privó definitivamente la pena de inhabilitación, fuese esta impuesta como accesoria o como principal. Se trata de un camino excepcional - un atajo, más bien- por el que el otrora funcionario (el procedimiento no está previsto para el empleado público no funcionario ${ }^{24}$ ) reingresará en el cuerpo correspondiente de forma directa, sin perjuicio de que el puesto de trabajo adjudicado con carácter provisional deba después ser convocado para su provisión definitiva por el procedimiento que corresponda (art. 8.2 R.D. 2669/1998). Para ello no deberá aguardar siquiera, en la mayoría de los casos, a la cancelación de sus antecedentes penales ${ }^{25}$, a diferencia de lo que ocurriría de facto de seguir la vía antes llamada ordinaria. Todo ello en virtud de una resolución administrativa, bien que sujeta al eventual control jurisdiccional.

A estudiar esta institución se dedica el apartado siguiente, por lo que en este momento quiere únicamente llamarse la atención sobre el hecho de que la convivencia de dos mecanismos encontrados de reincorporación dificulta la propia explicación unitaria de aquel sistema de inhabilitación y su fundamento. Pues, en efecto, de un lado existe una vía que exigirá ponderar administrativamente el impacto de la reincorporación valorando determinados criterios relativos a la sensibilidad del destino en el que debe reincorporarse (criterios, cabe pensar, orientados a ga-

${ }^{23}$ Así, puede verse el art. 380 en relación con el 379c) LOPJ, referidos a la rehabilitación de jueces o magistrados respecto de sanción disciplinaria de separación de la Carrera judicial, o el art. 493, párr. últ. del mismo cuerpo legal, así como el art. 76.3 R.D. 1451/2005, de 7 dic., en relación a la rehabilitación de los funcionarios al servicio de la Administración de Justicia. Véanse, también, arts. 46 y 70 del Estatuto Orgánico del Ministerio Fiscal (Ley 50/1981), art. 56.4 R.D. 1608/2005, de 30 dic., que aprueba el Reglamento Orgánico del Cuerpo de Secretarios Judiciales o art. 71 R.D. 296/1996, de 23 febr., Reglamento Orgánico del Cuerpo de Médicos Forenses. Cfr., asimismo, el art. 152 del Texto refundido que aprueba las disposiciones legales vigentes en materia de régimen local (R.D. Leg. 781/1986, de 18 de abril).

${ }^{24}$ En efecto, tanto el art. 68.2 EBEP como el art. 6.2 RD 2669/1998 se refieren solo a la condición de funcionario, por lo que no abarca a otro tipo de empleados públicos (PuENte Aba, L.M., en Faraldo Cabana, P./Puente Aba, L.M., (Dirs.), Las penas privativas de derechos ..., cit., p. 58). No obstante, aunque no por rehabilitación, sí podrán acceder por concurso pues, como se ha dicho, tanto el EBEP como el Real Decreto 364/1995, de 10 de marzo, señalan que les será aplicable el régimen general de los funcionarios, que no exige no haber sido inhabilitado, sino simplemente no hallarse en el momento en cuestión en inhabilitación absoluta o especial para empleos o cargos públicos por resolución judicial.

${ }^{25}$ Aunque sí la exigen algunas normas sectoriales (p..e., secretarios judiciales, médicos forenses o funcionarios al servicio de la Administración de Justicia). 
rantizar el prestigio y buen funcionamiento de la Administración). Pero, de otro, subsiste un sistema, si se quiere más oneroso para el interesado por cuanto requerirá la superación de determinadas pruebas de acceso, pero que permitirá a cambio acceder a cualquiera, sin valoración del supuesto impacto de su reincorporación por parte de la Administración de destino (más allá de la relativa a sus propios conocimientos) y aunque el aspirante no reúna aquellos requisitos que se suponen necesarios para salvaguardar el prestigio de la Administración ${ }^{26}$.

Este tipo de dicotomías, que dificultan el ofrecimiento de explicaciones unitarias o coherentes de todo el derecho dado, se observan también en otros aspectos de nuestro Derecho positivo, como en la previsión dispar del sistema de rehabilitación en las normativas autonómicas en relación con sus propios funcionarios (algunas sí la prevén, otras no), o como la mencionada imposibilidad (salvo excepciones) de rehabilitar las sanciones disciplinarias de separación del servicio y sí, en cambio, las inhabilitaciones penales, lo que plantea un nuevo reto de fundamentación si no se quiere ignorar la unidad de la potestad sancionadora del Estado.

\section{La rehabilitación administrativa tras condena penal}

\section{Concepto y régimen jurídico. El procedimiento de rehabilitación}

Vigente ya el Código actual, la Ley 13/1996, de 30 de diciembre, de medidas fiscales, administrativas y del orden social, en vigor desde el 1 de enero de 1997, introdujo, un tanto subrepticiamente, a través de su artículo 105, una importante modificación en el art. 37 del entonces vigente Decreto 315/1964, de 7 de febrero, por el que se había aprobado el texto articulado de la Ley de Funcionarios Civiles del Estado (LFCE). El citado artículo 105 modificaba de forma trascendente la regulación de la pérdida de la condición de funcionario estableciendo, entre otras nove-

26 Una vía intermedia parece la implantada por el reciente R.D. 728/2017, de 21 de julio, por el que se aprueba el Reglamento de adquisición y pérdida de la condición de Guardia Civil y de situaciones administrativas del personal de la Guardia Civil. En este caso, se combina una rehabilitación de carácter excepcional — atendiendo «a las circunstancias y entidad del delito cometido»- tras condena a pena principal o accesoria de inhabilitación absoluta o especial (que corresponde otorgar, en su caso, al Ministerio de Defensa), con la acreditación de la aptitud para prestar el servicio por parte del interesado: Para ello — dispone el art. 11.4- éste «deberá superar una prueba objetiva de conocimientos sobre normativa, procedimientos y técnicas profesionales, según se determine por parte de la Jefatura de Enseñanza, atendiendo al empleo y escala a la que se reincorporaría y, en su caso, otra correspondiente a las pruebas físicas que hubiera que superar para ingresar en su escala adaptadas a su sexo y edad. Igualmente, por el Servicio de Asistencia Sanitaria y por el Servicio de Psicología será sometido a reconocimientos médicos y a pruebas psicológicas a fin de acreditar la aptitud para el servicio». 
dades, que «Los Órganos de Gobierno de las Administraciones Públicas podr[ían] conceder la rehabilitación, a petición del interesado, de quien hubiera sido condenado a la pena principal o accesoria de inhabilitación, atendiendo a las circunstancias y entidad del delito cometido» ${ }^{27}$. En ese momento no se indicó siquiera - como hace en cambio la previsión homóloga actualmente en vigor (art. 68.2 EBEP)—, que dicha concesión hubiese de tener carácter excepcional. Tampoco contuvo particulares explicaciones sobre esta novedad la Exposición de Motivos de la citada ley de medidas fiscales, limitándose a señalar que «el Título III de la Ley acog[ía] una pluralidad de normas administrativas que se refier[ían] al personal al servicio de las Administraciones Públicas» ${ }^{28}$.

Es verdad que el art. 105 no se incorporó al ordenamiento del todo sin hacer ruido, pues fue objeto de una cuestión de inconstitucionalidad planteada por la Sala de lo Contencioso-Administrativo del TSJ de Galicia (registrada el 14 de junio de 2000), que fue, no obstante, inadmitida a trámite por el ATC núm. 47/2001, de 26 de febrero, en resolución que valdrá la pena recuperar más adelante al tratar sobre la naturaleza de esta institución ${ }^{29}$. Pero lo relevante ahora es que la disposición citada (que pasaría después al EBEP de 2007 y se mantiene en la versión de 2015) motivaría la necesidad de articular una regulación específica para vehicular aquella nueva posibilidad de reingreso ${ }^{30}$, lo que tuvo lugar a través del Real Decreto núm. 2669/1998, de 11 de diciembre, por el que se aprobaba el procedimiento a seguir en materia de rehabilitación de los funcionarios públicos en el ámbito de la Administración General del Estado, norma que continúa vigente y que sigue siendo la básica en la materia, si bien existen disposiciones específicas para ciertos funcionarios del Estado ${ }^{31}$ así como

27 En la versión original de la LFCE no se contemplaba la rehabilitación para casos de inhabilitación, limitándose la norma a señalar que la separación del servicio tenía carácter definitivo (art. 38).

${ }^{28}$ Aunque la idea de la rehabilitación del funcionario no podía considerarse, desde luego, innovadora. Ya el Código penal de 1870 la previó en su art. 45, indicando que "Los sentenciados á las penas de inhabilitación para cargos públicos, derecho de sufragio, profesión ú oficio, perpétua ó temporalmente, podr[ían] ser rehabilitados en la forma que determin[ase] la ley».

${ }^{29}$ Infra, III.2.

${ }^{30} \mathrm{Si}$ bien se ha señalado que los términos en los que se pronuncia la regulación del art. 68.2 EBEP permitirían su aplicación incondicionada, esto es, sin necesidad de ulterior concreción normativa (en este sentido, Palomar Olmeda, A., Derecho de la Función Pública. Régimen jurídico de los funcionarios públicos. 8. ${ }^{\mathrm{a}}$ ed. Dykinson, Madrid, 2009, p. 271).

31 Así, p. e., en el R.D. 728/2017, de 21 de julio, por el que se aprueba el Reglamento de adquisición y pérdida de la condición de Guardia Civil y de situaciones administrativas del personal de la Guardia Civil, o en el R.D. 1608/2005, de 30 de diciembre, por el que se aprueba el Reglamento Orgánico del Cuerpo de Secretarios Judiciales (arts. 56 a 60) - si bien los criterios a valorar son esencialmente coincidentes con los establecidos en el art. 6.2. R.D. 2669/1998-. Menciones específicas a la rehabilitación se contienen también en la L.O. 4/2010, sobre régimen disciplinario del Cuerpo Nacional de Policía (D.Ad. 1. ${ }^{\text {) }}$ o en la Ley 29/2014, de 28 de noviembre, de régimen del personal del Cuerpo de la Guardia Civil (art. 98). 
normas autonómicas, para el personal al servicio de estas últimas administraciones ${ }^{32}$.

Conforme a aquella norma general, el funcionario inhabilitado penalmente puede ser repuesto en su condición de tal en virtud de rehabilitación, sin pasar por la vía ordinaria de acceso ( $\sin$ perjuicio de que el puesto ocupado provisionalmente al inicio deba finalmente ser convocado para su provisión definitiva por el procedimiento que corresponda: art. 8.2 R.D. 2669/1998). En concreto, al funcionario rehabilitado se le asignará el desempeño provisional de un puesto de trabajo, tarea o función correspondiente a su Cuerpo o Escala, debiendo tomar posesión en el puesto adjudicado en el plazo de un mes si hubiera vacante disponible en el momento de la resolución (art. 8.1 R.D. 2669/1998) o, si no la hubiera, siendo acreditado en nómina por el órgano competente en el mismo plazo y sujetándose después para fijar su ocupación a las disposiciones en materia de asignación de puestos de trabajo a los funcionarios removidos ${ }^{33}$.

Para optar a la rehabilitación (no existe un derecho subjetivo automático a obtenerla ${ }^{34}$ ), resulta necesario haber extinguido las responsabilidades tanto penales como civiles (art. 2.3 R.D. 2669/1998), pero no se requiere, en cambio, la previa cancelación de los antecedentes penales ${ }^{35}$,

32 Contienen referencias específicas a la rehabilitación, p.e. y entre otras, las Leyes de Función Pública de Castilla y León (Ley 7/2005, de 24 de mayo, art. 37.2), de la Comunidad Valenciana (Ley 10/2010, de 9 de julio, art. 64.2) o del País Vasco (Ley 6/1989, de 6 de julio, art. 37.4). También la contiene, pero para negarla expresamente, la Ley de Función Pública de Illes Balears (Ley 3/2007, de 27 de marzo), cuyo art. 59.2 establece que la separación del servicio cuando deviene firme tiene carácter definitivo y no es posible la rehabilitación.

33 Según el art. 50.5 R.D. 364/1995, de 10 de marzo, por el que se aprueba el Reglamento General de Ingreso del Personal al Servicio de la Administración General del Estado y de Provisión de Puestos de Trabajo y Promoción Profesional de los Funcionarios Civiles de la Administración General del Estado «A los funcionarios removidos se les atribuirá el desempeño provisional de un puesto correspondiente a su Cuerpo o Escala, en el mismo municipio, no inferior en más de dos niveles al de su grado personal, en tanto no obtengan otro con carácter definitivo, con efectos del día siguiente al de la fecha del cese y de acuerdo con el procedimiento que fije el Ministerio para las Administraciones Públicas».

${ }_{34}$ En este sentido, entre otras muchas, las SSTS (Sala Cont., Secc. 7. ${ }^{\text {a) }}$ de 29 de junio núm. 1601/2016 (RJ 2016/4176), de 19 de noviembre de 2014 (Roj: 4908/2014), o de 18 de septiembre de 2006 (Roj: 5514/2006).

${ }_{35}$ Una precisión terminológica, tal vez innecesaria, pero que no debe inducir a confusión: al hablar de rehabilitación nos referimos en este trabajo al procedimiento regulado, básicamente, en el Real Decreto núm. 2669/1998, no al sentido del término como sinónimo de la cancelación de antecedentes penales, en el que no obstante se ha usado también tradicionalmente este término. Este último uso es consecuencia directa de la terminología expresamente utilizada por nuestro derecho histórico, pues con ese título, «De la rehabilitación», venía rubricado el capítulo II del Título V del Libro I del Código penal derogado (de 1944, Texto refundido de 1973), que contenía el art. 118, dedicado precisamente a la cancelación de antecedentes penales (exactamente igual que ya hicie- 
al menos con carácter general ${ }^{36}$. Se trata -intentando describir a grandes trazos el procedimiento establecido para la Administración del Estado- de un procedimiento que debe iniciarse a instancias del interesado (art. 4.1), que corresponde instruir a la Secretaría de Estado para la Administración Pública a través de la Dirección General de la Función Pública, y del que es competente para resolver - previo informe preceptivo de la Subsecretaría del Departamento que hubiera declarado la pérdida de la condición de funcionario- el Consejo de Ministros ${ }^{37}$ (art. 3.2), cuya resolución pone fin a la vía administrativa ${ }^{38}$. La resolución desestimatoria impide volver a plantear la solicitud hasta transcurridos dos años (art. 7.8 R.D. 2669/1998). Y el silencio, por su parte, debe considerarse, hoy, negativo ${ }^{39}$.

ra su predecesor, el Código penal de 1932, en su art. 121, presidido por idéntica rúbrica). El término se repetía, por lo demás, en más de media docena de ocasiones en los siete artículos que integraban el hoy derogado Real Decreto $n .^{\circ}$ 2012/1983, de 28 de julio, sobre cancelación de antecedentes penales, hoy sustituido por el Real Decreto 95/2009, de 6 de febrero, por el que se regula el Sistema de registros administrativos de apoyo a la Administración de Justicia. La implantación y arraigo del término en el sentido aludido no puede, pues, extrañar.

36 Sí la exigen, en cambio, algunas normas sectoriales. Así, el Reglamento Orgánico del Cuerpo de Secretarios Judiciales (R.D. 1608/2005, arts. 56.3 y 57.4), el Reglamento Orgánico del Cuerpo de Médicos Forenses (R.D. 296/1996, de 23 de febrero, art. 71.1) o la LOPJ, en relación con el Cuerpo de funcionarios al servicio de la Administración de Justicia (art. 493), al igual que hace el Reglamento de ingreso, provisión de puestos de trabajo y promoción profesional del personal funcionario al servicio de la Administración de Justicia (R.D. 1451/2005, de 7 de diciembre, art. 76.3).

37 Previsiones análogas se encuentran en las normas autonómicas en relación con los funcionarios al servicio de éstas.

38 Sin perjuicio del recurso de reposición, aunque el art. 7.7 R.D. 2669/1998 cite solo, directamente, el recurso contencioso-administrativo (ARRIBAS LÓPEZ, E., Sobre la rehabilitación de los funcionarios rehabilitados, Actualidad Administrativa, febr. 2017, n. ${ }^{\circ} 2$ ).

39 Pese a que el art. 7.3 R.D. 2669/1998 indica lo contrario, señalando que se entenderá estimada la solicitud en caso de haber transcurrido seis meses sin que se hubiera dictado resolución expresa, dicha previsión debió considerarse derogada por la posterior, y de superior rango, Ley 7/2007, del Estatuto Básico del Empleado Público, cuyo art. 68.2 instituyó expresamente el criterio opuesto, de silencio negativo (cfr., STS, Sala Cont., Secc. 7. ${ }^{\text {a }}$, de 22 de julio de 2014 -RJ 2014/4118; Roj: 3269/2014-; STS, Sala Cont., Secc. 4. ${ }^{\text {a }}$ 1201/2017, de 10 de julio - RJ 2017/3241-). Incluso en relación con normativas específicas que no contaban con esa previsión expresa (como la de la Guardia Civil, Ley 42/1999, de 25 nov.), la Jurisprudencia se había mostrado proclive a sostener el carácter negativo del silencio administrativo. Para ello se había invocado el carácter supletorio del EBEP (art. 2.5) o se había venido a dar valor a argumentos como el del art. 43.1 de la derogada Ley 30/1992: la excepción al silencio positivo que rechazaba que pudiese operar dicha figura cuando la estimación tuviera como consecuencia que se transfiriesen al solicitante o a terceros facultades relativas al dominio público o al servicio público, entendiendo la rehabilitación del funcionario como una muestra de esto último (STS, Sala Contencioso Adm., Secc. 4. ${ }^{\text {a }}$, de 24 de julio de 2012 -Roj: 4946/2012-).

Con anterioridad, es cierto, bajo la vigencia del art. 37.4 LFCE, el silencio se entendió en sentido positivo (p.e. en ese sentido, la STS de 17 de febr. de 2003 -Roj: 1039/2003 —). Cfr. Luque Parra, M., Pérdida de la relación de servicio, en Del Rey Guanter, S. (Dir.), Comentarios al Estatuto Básico del Empleado Público, La Ley, p. 731. 
Una vez presentada la cuestión en sus rasgos esenciales no se hace necesario extenderse más sobre la tramitación administrativa, pues más que el procedimiento en sí interesan a este trabajo los criterios en función de los cuales debe adoptarse la resolución, lo que se analizará, como se dijo, en el epígrafe IV, tras habernos interrogado por el fundamento que debe informar el funcionamiento de esta institución.

\section{Fundamento. La rehabilitación administrativa en el sistema de inhabilitación penal}

1. En sus resoluciones sobre la materia, la jurisdicción contenciosoadministrativa se ha encargado de subrayar el carácter netamente administrativo de la rehabilitación, intentando independizarla de la cuestión penal. Ya el propio Tribunal Constitucional manifestó en su momento, en el citado Auto núm. 47/2001, de 26 de febrero, mediante el que se inadmitía la cuestión de inconstitucionalidad formulada frente al art. 105.3 de la Ley 13/1996, que «la función rehabilitadora reconocida legalmente a la Administración despliega su eficacia exclusivamente en el ámbito administrativo, una vez que el funcionario condenado haya extinguido la responsabilidad penal impuesta en sentencia» y que - asumiendo en esto la posición mantenida entonces por el Fiscal General en su informe- la rehabilitación constituiría solo «una manifestación de la potestad reconocida en el art. 103.3 CE para configurar el régimen estatutario de los funcionarios públicos (una de cuyas manifestaciones es la de establecer mecanismos de acceso, pérdida y rehabilitación de la condición de funcionario - STC 99/1987, de 11 de junio-) al legislador, el cual ha decidido establecer determinados mecanismos de rehabilitación que no afectan a la pena impuesta por los Tribunales y que, por otra parte, obedecen a fines constitucionalmente legítimos, como son la reinserción social y la reeducación de los penados (art. 25.2 CE) (sic.)». En suma —sentenciaba literalmente el Tribunal Constitucional- «la rehabilitación que los órganos de gobierno de las Administraciones Públicas pueden conceder en nada afecta al cumplimiento de la pena de inhabilitación especial y sus consecuencias jurídicas» ${ }^{40}$. En la literatura científica administrativista se encuentran también opiniones que vienen a alinearse plenamente con esta separación tajante de la rehabilitación respecto del contenido penal de la inhabilitación, opiniones que comulgan, en suma, con este distancia-

40 De lo que deducía en esa ocasión — no sin cierto salto argumental - que «por consiguiente dicho precepto (ref. al art. 105.3 de la Ley 13/1996) no implica ningún ejercicio del derecho de gracia por parte de las Administraciones Públicas en relación a la sentencia penal, ni contempla un indulto de la pena de inhabilitación impuesta a los funcionarios, y por ello no presenta ninguna contradicción con el art. 62 i) CE, que atribuye a S.M. el Rey el ejercicio de aquella prerrogativa». 
miento de la cuestión administrativa respecto de la pena de la que, sin embargo, aquella a fin de cuentas trae causa ${ }^{41}$.

Pero la argumentación del TC reproducida admite, desde luego, alguna observación que merece la pena comentar, aunque no sea para cuestionar - vaya por delante- la constitucionalidad de la institución rehabilitadora en sí. Empezando por el último precepto invocado, debe tenerse de entrada presente que el envoltorio del art. 25.2 CE utilizado para vestir de mejor apoyatura constitucional a esta institución va en puridad referido a las penas privativas de libertad, no de derechos (y a las medidas de seguridad). Y aun en relación con la utilización de este mismo precepto como argumento debe observarse, sobre todo, lo llamativo y capcioso que resulta negar el parentesco de la institución rehabilitadora con las penas e invocar después para justificar dicha institución los fines que son propios de algunas de ellas, como la reinserción a la que se refiere el art. $25 \mathrm{CE}$. Por su parte, conviene notar también que el art. 103.3 CE no alude a la necesidad de regular por Ley una rehabilitación tras sentencia de inhabilitación, y que escudarse en este precepto en la forma en que se hace en la argumentación reproducida es, de hecho, eludir la cuestión de fondo. Cierto que dicho artículo indica que la ley regulará el estatuto de los funcionarios públicos y que una de sus manifestaciones puede ser —no debe necesariamente ser- la rehabilitación, pero ésta puede caber frente a diversas situaciones administrativas en las que se haya extinguido la relación de servicios, como de hecho ocurre y la Ley regula para los supuestos de pérdida de la nacionalidad o de jubilación por incapacidad permanente (art. 68.1 EBEP y R.D. 2669/1998). No está dicho, en cambio, que deba caber también ante situaciones establecidas penalmente. La cuestión de fondo, que esta argumentación sortea por la vía de darla por supuesta, es si cabe o no legítimamente la revisión por vía administrativa de efectos de la pena acordados por la jurisdicción penal, y a esta cuestión no contestó, en rigor, la meritada sentencia del Tribunal Constitucional. Realmente, al TC le bastó con fijarse en un aspecto colateral, producto de la forma en que se le planteó la cuestión. Y es que debe recordarse que la duda de constitucionalidad se vinculó por la Sala de lo Contencioso-Administrativo del TSJ de Galicia únicamente con la gracia del indulto, planteando su posible contradicción con la atribución en exclusiva al Rey de la potestad de perdonar las

${ }^{41}$ Señala CAMPOS DAROCA, por ejemplo, que esta potestad que permite a la Administración eximir de acudir a un proceso selectivo a una persona que ha sido privada de la relación de servicio en virtud de una pena de inhabilitación impuesta por sentencia penal, descansa en las facultades de auto-organización de la propia Administración Pública, viniendo a fundamentarla en las propias necesidades del servicio. Para el autor, así, la Administración puede simplemente entender que «ciertos funcionarios públicos son de cierta utilidad a la Administración Pública por lo que una vez cumplida la pena impuesta por el juez penal pueden reincorporarse al servicio público» (CAMPOS DAROCA, J.M., La extinción de la relación de servicio de los empleados públicos. Personal funcionario y laboral. Bosch, Barcelona, 2013, p. 96). 
penas impuestas por los órganos judiciales (art. 62.i) CE). Y para disipar esa duda, resultó suficiente poner el foco en un elemento diferencial entre ambas instituciones que, por lo demás, resulta notorio: mientras que el indulto extingue una responsabilidad penal pendiente (art. 130.4 CP) la función rehabilitadora parte justamente de un momento posterior, en el que el funcionario ha extinguido ya la responsabilidad penal (y hasta civil) impuesta. Pero siendo cierta - y evidente, como decía- esta diferencia entre la rehabilitación y el indulto, sigue en pie la cuestión de fondo indicada: si puede modificarse o no por vía administrativa la ejecución de un efecto penal.

$\mathrm{Al}$ respecto, a nadie se le escapa que la pretendida independencia del procedimiento de rehabilitación respecto de la sentencia penal no es tal en todos los planos, y que es cuestión que solo formalmente puede despacharse escudándose en su naturaleza administrativa. No puede obviarse que, si bien la rehabilitación tiene lugar una vez extinguida la responsabilidad penal, ello se refiere a uno solo de los dos contenidos de la pena de inhabilitación, el de carácter temporal, pero cabe tener en cuenta que, cumplido el periodo de privación impuesto, resta en pie el otro de los efectos de la pena en cuya ejecución, en realidad, se incide, quiérase o no, con la rehabilitación, pues dicho efecto había quedado ya perfeccionado, completo, con la firmeza de la sentencia condenatoria y el primer instante de su ejecución. En este sentido, la cuestión podría tal vez no haber tenido tan fácil escapatoria de haberse planteado en relación con la exclusiva competencia de Juzgados y Tribunales para hacer ejecutar lo juzgado (art. 117.3 CE).

Estas reflexiones no pretenden atacar - se reitera- la constitucionalidad de la rehabilitación (aunque sí puedan sugerir otros modelos, como mantener el seguimiento de la ejecución de las penas de inhabilitación pública también en instancias jurisdiccionales, como ocurre con penas de otra naturaleza). Simplemente quiere ponerse de manifiesto que la rehabilitación sí afecta a la ejecución de la pena impuesta - contrariamente a lo sostenido en aquella resolución - resultando la institución analizada inescindible de la pena de inhabilitación de la que trae causa y que, en coherencia con ello, su fundamentación debe ser abordada como el reverso de la fundamentación específica de aquella pena, en lugar de hacerlo al margen de ella, como si se tratase de una simple cuestión más del régimen estatutario de los funcionarios públicos. Ello afectará decididamente a los criterios que deban tomarse en consideración para valorar la rehabilitación.

2. Si lo anterior es, como creo, correcto, procede entonces fijar las líneas básicas del argumentario que puede legitimar y fundamentar el uso de la inhabilitación para empleo o cargo público como pena en el Derecho punitivo actual. La imagen en negativo de ese cliché deberá ser la que, en su caso, fundamente después la institución rehabilitadora e inspire en consecuencia su regulación positiva. Al respecto, lo primero 
que resulta obvio es que la fundamentación de la pena de inhabilitación pública debe distanciarse absolutamente de los tintes infamantes que acompañaron a esta clase de sanción en sus orígenes. La dignidad de la persona, consagrada hoy en el art. $10 \mathrm{CE}$, hace innecesario cualquier otro abundamiento sobre este extremo. Tampoco su utilidad es, sin más, su justificación. La inhabilitación para la función pública es ciertamente capaz de cumplir satisfactoriamente los fines propios de una pena, tanto retributivos - por su innegable carácter aflictivo (aunque se proyecte de forma desigual en función de las expectativas profesionales del destinatario) - como preventivos, generales y especiales, y ello con mayor precisión si cabe que una consecuencia punitiva de amplio espectro, como puede ser la privación de libertad. Pero no por útil, decíamos, una consecuencia se torna necesariamente en legítima. En el panorama actual, la inhabilitación para la función pública encuentra su justificación específica en la salvaguarda del prestigio y credibilidad de la Administración Pública que resultan indispensables como instrumentos para su adecuado funcionamiento y consiguiente servicio, con objetividad, a los intereses generales. Su destacado carácter aflictivo, por otra parte, debiera llevar a un uso decididamente restrictivo ${ }^{42}$, por la contundencia de sus efectos definitivos, prefiriendo la pena de suspensión en todos aquellos casos en los que ésta resulte político-criminalmente suficiente, en lugar de operar esa mutación a posteriori, en sede administrativa.

Pues bien, en tal contexto, concebida como reverso de las razones específicas de la pena, la rehabilitación solo podrá obedecer a la apreciación, con carácter claramente excepcional, de circunstancias sobrevenidas que permitan concluir que, pese a que el hecho en abstracto fue conminado con la pérdida definitiva de la condición de funcionario, la confianza social en la Administración Pública no se resentirá con la reincorporación del condenado. No se trata, por tanto, de determinar si se han recuperado ciertas aptitudes por parte del reo (que seguramente nunca perdió), ni de valorar aspectos como su reeducación, el pronóstico de peligrosidad (no determinable respecto de sujetos imputables) o el carácter especialmente oneroso que para el concreto individuo pueda representar la separación indefinida de la función pública (p. e., por hallarse en situación de precariedad económica), sino, simple y llanamente, de comprobar si en las circunstancias concretas, una vez extinguida la responsabilidad penal y civil, concurren factores posteriores a la condena que permitan concluir que la Administración está en condiciones de soportar que ese condenado en concreto se reincorpore sin que la confianza social en ella se resienta por ese motivo. Tener en cuenta este factor constituiría desde luego una mons-

${ }^{42}$ No obstante, y solo tomando en consideración su uso como pena principal, las inhabilitaciones para cargo público se prevén actualmente en casi centenar y medio de ocasiones en nuestro Código (entre inhabilitaciones absolutas y especiales). 
truosidad si se usase para fundamentar su pena, por cuanto ésta no se haría depender entonces del hecho, sino de circunstancias externas y hasta aleatorias, ajenas a su responsabilidad (p. e., el propio impacto mediático del delito cometido). Sin embargo, ese fantasma no afecta a la cuestión, desde el momento en que la pena justa, la adecuada a la gravedad del hecho, se ha establecido en función de otros parámetros. Que el sujeto pueda verse privado definitivamente de su medio de vida es una situación cuya gravedad ha sido (debería haber sido al menos) ya abarcada en el momento de seleccionar la pena en abstracto y, por tanto, contando con la más que alta probabilidad de que el reo no pueda volver a incorporarse.

Como otras instituciones vinculadas no al merecimiento sino a la necesidad de pena, la rehabilitación no es un derecho (en cuyo caso debería ser igualitario), sino una mera oportunidad excepcional de levantamiento de determinados efectos de la pena, una vez conclusos los efectos temporales, si, por razones no igualitarias y en el futuro (no, por tanto, en virtud de circunstancias ya valoradas o valorables en el momento de su imposición), concurren elementos que lleven al órgano correspondiente - tribunal o, en este caso, a la Administración (con el control judicial $)^{43}$ - , a juzgarlos innecesarios para mantener la credibilidad y el prestigio de la Administración, como instrumento que es para servir con objetividad los intereses generales.

3. A partir de las anteriores reflexiones, podemos dirigir la mirada a la Jurisprudencia de los últimos años para valorar en cuánto coinciden con ellas las resoluciones de la jurisdicción contencioso-administrativa. $\mathrm{Al}$ respecto, y aunque los argumentos aparecen generalmente enredados, pueden separarse dos grandes líneas de fundamentación de la rehabilitación administrativa.

Un primer planteamiento viene a situar el centro de gravedad en el interés del propio condenado, fijándose en que la pena pueda resultar excesiva para su concreto caso. En repetidas ocasiones se lee así en

${ }^{43} \mathrm{Al}$ igual que debe exigirse una mayor implicación del órgano judicial para la imposición de la pena de inhabilitación (que peca actualmente de un cierto automatismo, queda excluida del debate contradictorio y se ve afectada por una apreciable laxitud en la determinación de su propio contenido), es también legítimo proponer una mayor implicación judicial en el seguimiento de su ejecución, demandando que ésta y sus vicisitudes (incluida la rehabilitación) queden en el ámbito judicial, sea o no en manos del propio tribunal sentenciador. En este sentido pueden encontrarse sugerencias de interés, p. e., en el ordenamiento alemán, donde la inhabilitación para cargos públicos se configura como una consecuencia accesoria de la pena (Nebenfolge), previendo el §45b StGB el restablecimiento de las capacidades y derechos de los que se ha privado por parte del tribunal, a valorar una vez hecha efectiva la mitad del tiempo que debía durar (si bien debe tenerse presente que esta valoración se orienta a determinar que el condenado no cometerá en el futuro más hechos punibles dolosos, en línea del pronóstico de peligrosidad del sujeto que inspira las medidas de seguridad). 
resoluciones de la Sala Tercera que «la idea o finalidad presente en la rehabilitación es la siguiente: determinar si la incapacidad para ser funcionario, que en principio lleva consigo la condena penal de inhabilitación, resulta excesiva en algunos casos cuando el delito es ajeno al cargo funcionarial que se desempeñaba, no ha habido perjuicio para el servicio público y tampono los hechos han tenido tanta gravedad» ${ }^{44}$. Este enfoque vendría a fundamentar la institución rehabilitadora en una suerte de búsqueda de la justicia material del caso, lo que la aproximaría a la fundamentación del indulto, que debe pretender justamente (si se sigue una adecuada reinterpretación constitucional de este instituto) la realización de la justicia cuando de la estricta aplicación de la Ley resulte una consecuencia excesiva en el caso concreto. De hecho, aunque existen - como se ha dicho- diferencias obvias en el funcionamiento de ambas instituciones (operando la rehabilitación solo una vez que se ha extinguido la responsabilidad penal ${ }^{45}$ ), ambas cuentan también con importantes puntos de conexión, como el carácter excepcional que debe regir su aplicación (pese a que históricamente el indulto pueda haber conocido aplicaciones incluso masivas), o la intervención en ambos procedimientos del Consejo de Ministros.

${ }^{44}$ Pueden verse, entre las más recientes, las SSTS de la Sala Tercera, Secc. 7. a, núms. 1021/2017, de 10 de julio (RJ 2017/3241) o 912/2016, de 26 de abril (RJ 2110/2016). También, entre otras muchas, SSTS de 9 de octubre de 2006 (Roj: 5969/2006), de 14 de julio (Roj: 5159/2004) o de 17 de octubre (Roj: 6379/2003).

${ }_{45}$ Mientras que el indulto opera en una fase previa, extinguiendo una responsabilidad penal aún vigente. En este sentido, el indulto no conlleva por sí mismo el eventual reingreso en la función pública, sino que simplemente sitúa al reo en la posición que le permitirá optar a ello, como cualquier ciudadano, bien sea por el procedimiento ordinario de acceso (tras el tiempo necesario para la cancelación de sus antecedentes penales, si lo requiriese el cargo), bien por el extraordinario de la rehabilitación (sin necesidad en este caso de cancelación de antecedentes). La no automaticidad del reingreso es, si cabe, aun más evidente en los supuestos de indulto parcial (véase, STS, Sala de lo Contencioso, Secc. 7. a , de 5 de febr. de 2007 -Roj: 569/2007-).

El argumento para negar al indulto la anulación del efecto permanente de la inhabilitación, esto es, para negar que aquel implique la reincorporación automática a la función pública, se ha visto en el hecho de que tal efecto ya ha sido ejecutado de forma instantánea en el momento inicial de la sanción. En este sentido, para PUENTE ABA — La pena de inhabilitación especial ..., cit., p. 92; de la misma, La pena de inhabilitación absoluta ..., cit., p. 116 ss. - el perdón podría recaer sobre ambos efectos de la sanción sólo si se hubiera decretado la suspensión provisional de la ejecución de la pena mientras se tramita el expediente de indulto, en la medida en que solo en ese caso el efecto de la privación definitiva no se habría aún ejecutado. No obstante, debe apuntarse que la posibilidad de que el indulto abarque la reincorporación, sin rehabilitación previa, ha sido una cuestión controvertida en ciertos casos. De particular interés al respecto, la Sentencia del Tribunal de Conflictos de Jurisdicción de 13 de junio de 2001, BOE núm. 166, de 12 de julio (caso Gómez de Liaño). Véase, también, Llorca Ortega, J., La Ley de Indulto (Comentarios, Jurisprudencia, Formularios y notas para su reforma), 3. ${ }^{\text {a }}$ ed., Tirant lo Blanch, Valencia, 2003, p. 35 ss.; Aguado Renedo, C., Análisis (estrictamente jurídico) de un indulto conflictivo: el caso "Gómez de Liaño», Rev. Española de Derecho Constitucional, n. ${ }^{\circ}$ 63, 2001, pp. 279 ss. 
Sin embargo, y al margen de otras consideraciones, las razones atendibles para adecuar el caso a la justicia material en el indulto son del todo distintas a las que se vienen a usar para justificar la rehabilitación desde este pretendido enfoque de la misma, como atemperadora del rigor de la pena. Mientras que con el indulto - correctamente entendidopueden venir a ponderarse aspectos como la existencia de necesidades preventivo especiales no canalizables mediante el sistema progresivo de ejecución o mediante sustitutivos penales, la existencia de errores judiciales no subsanables mediante la vía de recursos o el hecho de que el sujeto haya podido padecer por alguna circunstancia una poena naturalis, la rehabilitación enfocada como modulación de la gravedad de la pena viene a suponer en realidad una revisión inadmisible de los criterios barajados bien para la determinación legal de la pena, bien para su determinación judicial. Con este criterio se procede así, en algunos casos, bien a re-calibrar la gravedad del hecho en abstracto, enmendando así la plana al legislador al decidir por vía administrativa que era excesiva la inhabilitación para conminar determinado comportamiento, y considerar de facto preferible la suspensión (que es aquello en lo que se convierte la pena por la vía de la rehabilitación), bien a re-enjuiciar los hechos, modulando en este caso la decisión judicial (p. e., tomando en consideración la concurrencia de ciertas atenuantes, como la de reparación). En ese mal incurren directamente, a mi juicio, algunos de los criterios enumerados por el propio art. 6 R.D. 2669/1998, que deberán por ello valorarse críticamente (Infra, IV). Si el hecho en abstracto tiene relación con el cargo funcionarial u ostenta gravedad suficiente, es algo que el legislador no solo está en condiciones de determinar a priori sino que le compete precisamente a él determinar, sin que resulte justificado valorarlo de nuevo, en sentido eventualmente opuesto, en sede de rehabilitación ${ }^{46}$. Tampoco parece justificado, por otro lado, volver a valorar los hechos probados en la sentencia penal o las circunstancias que llevaron a configurar la concreta responsabilidad criminal $^{47}$, como de hecho se hace, enmendando en este caso la plana al juzgador.

Por ello, un segundo enfoque resulta a mi juicio más adecuado al fundamento que debe guiar el funcionamiento de la rehabilitación.

46 Cuestión distinta es que las deficiencias o irregularidades del sistema contemplen inhabilitaciones ajenas al ejercicio de la función pública, como ocurre con la inhabilitación absoluta accesoria, y ello parezca dejar un nicho específico de actuación a la rehabilitación valorando la falta de relación con el cargo.

47 En sentido contrario, ARRIBAS LÓPEZ, E., Sobre la rehabilitación de los funcionarios inhabilitados, Actualidad Administrativa, n. ${ }^{\circ}$ 2, febr. 2017, p. 5, quien considera justamente que para la rehabilitación deben valorarse, siguiendo los criterios orientadores del art. 6.2 R.D. 2669/1998, «los hechos probados en la sentencia penal, las circunstancias concurrentes y los elementos que han configurado la responsabilidad criminal del autor». El autor recalca precisamente en este sentido la similitud de la rehabilitación, salvando las distancias, con el indulto, como mecanismo atemperador del rigor que puede tener la pena. 
Aquél que situaría el centro de gravedad de esta institución en la tutela o aseguramiento de la credibilidad y prestigio de la propia Administración Pública, en lugar de situarlo en el interés del condenado. Esta perspectiva aflora también en algunas resoluciones judiciales que se fijan no en el carácter eventualmente excesivo de la privación definitiva del empleo o cargo (lo que debería canalizarse en su caso por la vía del indulto), sino en si la imagen de la Administración se resiente o no como consecuencia de la reincorporación de un determinado funcionario ${ }^{48}$.

No obstante, como se ha dicho, los argumentos de ambas perspectivas - junto con los de alguna otra posición jurisprudencial más aislada, como la que viene a fijarse en la capacidad personal del acusado para el cargo $^{49}$ - aparecen frecuentemente entremezclados, incluso en la misma resolución, pudiendo llegar a advertirse un punto de convergencia en la valoración del carácter excesivo de la sanción, pero ponderado respecto de la protección de los intereses de la Administración. En este sentido, en algunas resoluciones se desatienden tanto circunstancias personales del condenado - como la precariedad económica que pueda sufrir por su falta de empleo, la superación de adicciones que pudieron afectarle en el momento de los hechos o el pronóstico de que personalmente pueda afrontar con solvencia y garantías las funciones de su cargo- como circunstancias indicativas de la menor gravedad del hecho cometido (reflejada en la propia duración, escasa, de la pena impuesta), para primar en cambio la salvaguarda de la imagen de la Administración. Así, por ejemplo, en la STS de 5 de julio de 2016, se denegó la rehabilitación de un funcionario de prisiones condenado por un delito contra la integridad moral por haber cortado la coleta a un recluso del Hospital Psiquiátrico de Sevilla. Los hechos, pese a ser absolutamente execrables - lo que será a la postre lo relevante-, objetivamente no pertenecían a los de mayor gravedad entre los de su especia, atentatorios contra la integridad moral, habiendo sucedido mucho tiempo atrás (trece años antes) y merecido únicamente una pena de inhabilitación especial de dos años; desde el punto de vista personal, la capacidad del autor para el desempeño del servicio no ofrecía tampoco dudas, siendo que de hecho había vuelto a prestar servicio como funcionario del Cuerpo de Ayudantes Penitenciarios tanto en oficinas como en contacto con la población interna sin ninguna incidencia y de manera ininterrumpida durante cuatro años (en un reingreso que fue anulado por no haberse seguido en esa ocasión el procedimiento oportuno). Es el descrédito de la Administración que se asocia a la reincorporación, por la naturaleza del hecho y por encima de cualquier otra consideración, lo que tendrá el peso decisivo para denegar la rehabilitación.

48 P. e., STS 1021/2017, Sala Cont., Secc. $4 .^{\text {a }}$, de 10 de julio (RJ 2017/3241); STS Sala Cont., Secc. $7 .^{\text {a }}$, de 1 de julio de 2015 (RJ 2015/3900).

${ }_{49}$ P. e., STS, Sala Contencioso-Administrativo, Secc. 7. ${ }^{\mathrm{a}}$, de 1 de julio de 2015 (RJ 2015/3900; Roj: 3623/2015). 
$\mathrm{Y}$ es que, en el fondo, se observa que se ha ido consolidando en la Jurisprudencia, especialmente en los últimos años, una distinción a efectos de rehabilitación en función de la propia naturaleza del delito, separándose, no sin artificiosidad al carecer de una apoyatura legal concreta, entre unos ilícitos que afectarían a los «deberes esenciales» de todo empleado público (entre los que se encontrarían los delitos contra la salud pública o de detención ilegal, por ejemplo) y otros que (supuestamente) no conculcarían tales deberes esenciales, y en relación con los cuales la Jurisprudencia se muestra más proclive a la rehabilitación (así, en la comisión de delitos de naturaleza esencialmente económica en los que se haya restituido lo sustraído o defraudado). La bondad de esta distinción podrá compartirse o no, pero lo que resulta evidente conforme a las pautas hasta aquí expuestas es que esta clasificación (o la que en su lugar fuere) operada en función de la naturaleza de los delitos debería ser realizada por el legislador, prefiriendo en los casos correspondientes la pena de suspensión y evitando que sea la vía administrativa quien acabe modulando esa decisión. Esas mismas pautas nos han de permitir también, a continuación, pasar a valorar individualmente los concretos criterios de rehabilitación enumerados en el R.D. 2669/1998 y el uso que de ellos se ha venido haciendo, tanto por la Administración como por parte de nuestros tribunales.

\section{Criterios de rehabilitación. Revisión}

1. Si bien, como acaba de verse, la jurisprudencia ha terminado diseñando pautas específicas para decidir acerca de la rehabilitación del funcionario - como la clasificación de delitos aludida-, éstas parten de la aplicación de criterios normativamente establecidos. La norma fundamental en la materia, el tantas veces aludido R.D. 2669/1998, señala en su art. 6.2 que «para la resolución del procedimiento de rehabilitación de quienes hubieran perdido su condición de funcionario como consecuencia de haber sido condenados a pena principal o accesoria de inhabilitación, se tendrán en cuenta los siguientes criterios orientadores para la valoración y apreciación de las circunstancias y entidad del delito cometido:

a) Conducta y antecedentes penales previos y posteriores a la pérdida de la condición de funcionario.

b) Daño y perjuicio para el servicio público derivado de la comisión del delito.

c) Relación del hecho delictivo con el desempeño del cargo funcionarial.

d) Gravedad de los hechos y duración de la condena.

e) Tiempo transcurrido desde la comisión del delito. 
f) Informes de los titulares de los órganos administrativos en los que el funcionario prestó sus servicios.

g) Cualquier otro que permita apreciar objetivamente la gravedad del delito cometido y su incidencia sobre la futura ocupación de un puesto de funcionario público».

Según la propia dicción legal se trata, como se ve, de un catálogo de directrices meramente orientativas, por un lado, y de un catálogo abierto, no tasado, por otro, como evidencia la cláusula de cierre enumerada en último lugar. Esta elasticidad en los criterios aplicables hace que en la práctica -no puede silenciarse este extremo- la resolución de los supuestos de rehabilitación esté teñida de una fuerte imprevisibilidad en cuanto a la argumentación ${ }^{50}$, siendo, eso sí, la resolución denegatoria la apuesta más segura en cuanto al resultado, pues prosperan un número porcentualmente reducido de peticiones.

2. Antes de acometer el análisis individualizado de los criterios enumerados, se mencionan algunas características generales extraídas de la aplicación jurisprudencial de todos ellos. Destacaré las cinco siguientes:

a) En primer lugar, la mencionada excepcionalidad de la rehabilitación, que - no puede negarse- se traduce en una cierta predisposición hacia la resolución denegatoria. La jurisprudencia ha sido, en efecto, constante al afirmar que se trata de una fórmula excepcional (así lo proclama hoy, además, el propio EBEP, en su art. 68.2), manifestando que «el expediente de solicitud de rehabilitación en la condición de funcionario no es un procedimiento sancionador, sino un medio por el cual puede concederse con carácter excepcional la rehabilitación atendiendo a unos criterios orientadores establecidos en la normativa aplicable» (STS de 12 de junio de 2014), distanciándose en su uso del fin de reinserción social propio de las penas, que no es —se señala expresamenteel perseguido por la rehabilitación (STS de 10 de nov. de 2008).

50 Solo a título de ejemplo: la concurrencia de la atenuante de arrepentimiento y reparación del daño es valorada favorablemente en un buen número de resoluciones (STS núm. 1021/2017, Sala Cont., Secc. 4. ${ }^{a}$, de 10 de julio -RJ 2017/3241-, STS de 14 de julio de 2004 -Roj: 5159/2004— o STS de 16 de septiembre de 2013 -Roj: 4619/2013-) pero no lo es en otras (vg., STS de 14 de oct. 2010 -Roj: 5224/2010-). Lo mismo sucede con la reiteración delictiva: los hechos de los que trae causa la STS de 16 de sept. 2013 (RJ 2013/6344; Roj: 4619/2013), p.e., (cuatro años de inhabilitación absoluta, por delito de malversación) se repitieron en varias ocasiones, lo que no fue obstáculo para conceder la rehabilitación. En su sentencia de 1 de julio de 2015 (RJ 2015/3900), sin embargo, la Sala de lo Contencioso del TS (Secc. 7. ${ }^{\mathrm{a}}$ ) denegó la rehabilitación (tres años de inhabilitación especial, por falsedad en documento oficial) en un supuesto en que los hechos constituyeron "una conducta aislada y no continuada en el tiempo», circunstancia sin embargo previamente valorada en sentido favorable en este caso por la sentencia de instancia, la STSJ Cataluña (Sala Contencioso-Adm., Secc. 4. ${ }^{\mathrm{a}}$ ), n. ${ }^{\circ}$ 93/2014, de 4 de febrero (RJCA 2014/384) que había concedido la rehabilitación. 
b) En coherencia con lo anterior, la misma jurisprudencia ha reiterado que el procedimiento debe resolverse con sujeción a exigencias estrictas de motivación (SSTS de 28 de octubre de 2009; 29 de febrero de 2012; 19 de noviembre de 2014 o 10 de julio de 2017), llegándose a hablar recientemente de la necesidad de que concurran «motivos cualificados» para su concesión (así, STS de 5 de julio de 2016).

c) Se señala, asimismo, que la decisión rehabilitadora constituye una decisión potestativa para la concreta Administración concedente, pero no una decisión libre o discrecional, sino que debe resolverse conforme a los criterios normativamente establecidos en el art. $6.2^{51}$ (STS de 16 de septiembre de 2013, FJ 4. ${ }^{\circ}$; STS de 26 de abril de 2016). Con todo, resulta obvio que el procedimiento de rehabilitación no se inscribe en el marco de la potestad reglada de la Administración, sino de la potestad discrecional, solo condicionada a que sus actos se correspondan con los fines que justifican su actividad, sin desviación de poder (STS de 16 julio de 2002).

d) En el uso de los criterios normativamente dispuestos, se precisa que la ponderación de los mismos debe hacerse «con pautas cualitativas», lo que significa que bastará para considerar justificada la denegación de la rehabilitación con que uno de ellos opere en términos que reflejen en un nivel muy elevado «la incapacidad en el cometido profesional al que estuvo referida la pena de inhabilitación, aunque puedan concurrir otros que no tengan ese significado negativo» (v. g., STS de 26 de abril de 2016).

e) Y se puntualiza a la vez - lo que resulta destacable para completar esta visión general del procedimiento seguido en nuestro sistema- que la aplicación de tales criterios «ha de hacerse casuísticamente, ponderando las singulares circunstancias de cada situación». Ello se traduce en que "tratándose de condenas penales derivadas de delitos de la misma naturaleza, la rehabilitación concedida en un determinado caso no será extrapolable a otro diferente cuando no sean idénticos los hechos determinantes de una y otra condena penal, pese a ser encuadrables en el mismo o semejante tipo penal» (v. g., STS de 1 de julio de 2015).

Innecesario es recalcar que la relativización que en el uso de estos criterios entrañan las consideraciones vertidas en las letras d) y e) precedentes fomentan la incertidumbre aludida en su aplicación.

3. Descendiendo a los criterios reglamentariamente establecidos en particular, hay que señalar que si bien una parte de ellos pueden ser

51 Si bien, como se ha visto, la jurisprudencia ha derivado de ellos otros criterios propios, como la clasificación de delitos rehabilitables en función de su naturaleza. 
entendidos desde el punto de vista del impacto que la rehabilitación tendría sobre la credibilidad y confianza en la Administración Pública, y en ese sentido podrían resultar admisibles conforme a la posición aquí defendida siempre que se utilicen en esa concreta clave interpretativa, existen sin embargo otros en los que ello no es así. A este último grupo pertenecen la relación del hecho delictivo con el desempeño del cargo funcionarial, mencionado en el apartado c), la gravedad de los hechos, mencionada tanto en el apartado d) (junto a la consiguiente duración de la condena) como en la cláusula de cierre (apartado g), - ahora con el rango superior de principio general con el que cribar la entrada de otros posibles criterios no mencionados expresamente-) y, finalmente, la referencia a la conducta y antecedentes penales previos a la pérdida de la condición de funcionario.

4. Empezando por este último, no puede hacerse abstracción, de entrada, del riesgo que un criterio de valoración así representa en orden a inclinar el procedimiento hacia un censurable derecho penal por la conducción de vida, regusto que desprende inevitablemente este elemento. No puede ignorarse que tomar en consideración los antecedentes penales a efectos de rehabilitación supone ampliar el elenco de utilidades de una institución en sí misma cuestionable, al contrariar los fines resocializadores e implicar una capitis diminutio ${ }^{52}$ de los condenados, a los que se estigmatiza de facto con la condición legal de personas de segunda categoría $^{53}$, razones por las cuales sus usos deberían ser especialmente restrictivos ${ }^{54} \mathrm{y}$ cuidadosamente justificados ${ }^{55}$. Pero existen otras razones específicas que hacen que no sea éste un criterio de valoración recomendable (al menos, con claridad, por lo que se refiere a los antecedentes previos a la sentencia firme de inhabilitación). En primer lugar, hay que tener en cuenta que el fundamento del juicio de rehabilitación no es, según aquí se ha defendido, la confección de un pronóstico de peligrosi-

52 Ya en este sentido, BuEno ARús, F., Una nota sobre la rehabilitación en el Código penal español, Boletín del Ministerio de Justicia, n. ${ }^{\circ} 1111,25$ de octubre de 1977.

53 Mapelli Caffarena, B., Art. 136, en Gómez Tomillo, M., (dir.) Comentarios al Código

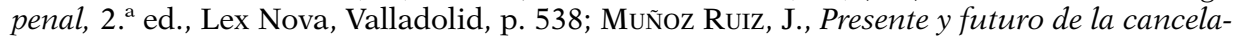
ción de los antecedentes delictivos, CPC, n. ${ }^{\circ} 112,2014$, p. 197.

54 Pese a ello, se ha asistido en los últimos tiempos a una tendencia expansiva de esta institución. Actualmente, la vigencia de los antecedentes penales resulta relevante a efectos de reincidencia $\left(22.8 .^{\mathrm{a}} \mathrm{CP}\right)$, de determinación de la pena $\left(66.5 .^{\mathrm{a}} \mathrm{CP}\right)$ o medida (art. 95.2 CP) y de suspensión de la pena privativa de libertad (80.2 CP). Pero también a efectos procesales (503.2 LECrim., prisión preventiva) y otros (p.e., la capacidad para ser jurado, art. 9 LOTJ).

55 En doctrina se propone, de hecho, bien su supresión, bien su uso exclusivo en relación con determinados delitos (Mapelli Caffarena, B., Art. 136, en Gómez Tomillo, M., Comentarios al Código penal, 2. ${ }^{\text {a }}$ ed., Lex Nova, Valladolid, p. 538) procurando en todo caso no contrariar las metas resocializadoras constitucionalmente establecidas y evitando en la medida de lo posible la discriminación adicional del condenado (MuÑoz RuIZ, J., Presente y futuro ..., cit., p. 197; Pozuelo Pérez, L., Cancelación de antecedentes delictivos, en Memento Práctico Penal, Francis Lefebvre, 2016, p. 719). 
dad del sujeto, de donde se desprende que los antecedentes que hubiera podido acumular el infractor hasta el momento de su inhabilitación no han de resultar relevantes. Por otro lado, si se trata de antecedentes penales previos a la inhabilitación, éstos habrán sido ya tenidos en cuenta en la pena que se impuso, bien fuese para agravarla, si resultaban computables, bien para ignorarlos, en caso contrario. Considerarlos de nuevo a otros cualesquiera efectos que incidan en la gravedad del cumplimiento de la condena no deja de suponer una doble valoración difícilmente justificable. En tercer lugar, hay que notar que se alude a los antecedentes sin distinción. Esta invocación genérica, por su vaguedad, debiera por sí sola invalidar el criterio. Al contrario de lo que sucede con sus efectos más importantes, el R.D. 2669/1998 no especifica —ni discrimina- si debe tratarse de antecedentes penales cancelados o no, como no especifica tampoco si debe tratarse de delitos de cierta gravedad o de la misma o similar naturaleza (lo que, caricaturizando el criterio, permitiría teóricamente ponderar para la rehabilitación la comisión de cualquier delito, previo incluso a la propia incorporación a la función pública). De hecho, si se trata de antecedentes anteriores a la pérdida de la condición de funcionario, aquéllos constituirán o bien antecedentes cancelados, que no le impidieron en su momento el acceso a la función pública, o bien antecedentes por delitos que no comportaban penas de inhabilitación.

Las consideraciones generales efectuadas sobre los antecedentes penales resultan asimismo extensibles a los generados con posterioridad a la pérdida de la condición de funcionario, a los que también se refiere como posible criterio a considerar en el expediente de rehabilitación la letra $a$ ) del art. 6.2. Sin embargo, en la medida en que la profesión pública en cuestión puede requerir la carencia de tales antecedentes para el acceso por la vía ordinaria (p. e., art. 303 LOPJ, para el acceso a la carrera judicial ${ }^{56}$ ), este extremo podría ser paralelamente considerado en esos casos también para conceder el acceso por la vía extraordinaria, siempre centrándose no tanto en el hecho mismo de la comisión previa de un delito sino en el eventual impacto que la reincorporación pudiese tener en la en la confianza social en la Administración afectada, que es a mi juicio el criterio rector que debe guiar la aplicación de esta institución.

Precisamente, si se acepta que los antecedentes penales eventualmente acumulados con posterioridad a la inhabilitación deben tener efectos en este campo (aunque, por lo dicho, se propugna con carácter

56 Que declara incapacitados, entre otros, «a los condenados por delito doloso mientras no hayan obtenido la rehabilitación» (entendiendo por tal la cancelación de antecedentes penales). Una vez obtenida la cancelación, el condenado podría concursar por las vías de acceso previstas, como la oposición o el cuarto turno. Vid., con claridad, STC 174/1996, de 11 de noviembre. 
general el uso restringido), lo procedente sería, a mi juicio, acompasar rehabilitación y antecedentes con criterios objetivables, y prescindir de la invocación inespecífica - y maleable - contenida actualmente en el art. 6.2. a) R.D. 2669/1998. Criterio objetivo puede ser —se insiste, si se da importancia a los antecedentes también en este campo- tener éstos cancelados -o ser cancelables-, al igual que se exige de forma objetiva, p. e., la extinción de la responsabilidad civil ${ }^{57}$. Téngase en cuenta que, en la situación actual, puede darse la paradoja de que el delito conserve aún la responsabilidad latente que implica la vigencia del antecedente penal y se proceda no obstante a la rehabilitación en supuestos en los que está vedado por esa circunstancia el acceso por la vía ordinaria ${ }^{58}$.

Por su parte, la gravedad de los hechos o del delito cometido (que son las dos expresiones que emplea el R.D. 2669/1998), no pueden ser, al menos conforme al fundamento de la institución aquí expuesto, criterio válido con el que dirimir la rehabilitación. Usándolos se incurre, de entrada, en un cuestionable bis in idem al valorar la misma circunstancia o circunstancias para imponer el castigo, primero, y para prolongarlo, después (ya que, como se ha fundamentado en este trabajo, la decisión sobre la rehabilitación no es independiente de la pena como a veces se pretende, sino que incide en un aspecto concreto de su ejecución). Por otra parte, fijarse en la gravedad de los hechos supone asumir una limitación no legalmente establecida, cual es la de aceptar que existen delitos (sin determinar) que no son rehabilitables, decisión posible y legítima, pero que compete al legislador tomar.

Nótese que lo que aquí se cuestiona no es que la gravedad del hecho pueda determinar la imposibilidad de reingresar en la función pública. Existen delitos (a mi juicio podrían ser los atentatorios desde la función pública contra derechos fundamentales - como torturas, detenciones- o contra determinados aspectos del orden constitucional, que sostiene a la propia función pública) cuya comisión hace difícil valorar después una reincorporación como inocua para la confianza social en la Administración, lo que bien puede llevar a considerarlos irreversibles en este punto, del mismo modo en que en virtud de otras consideraciones se pueden declarar imprescriptibles determinados ilícitos por considerar, en abstracto, que no dejarán por el paso del tiempo de afectar a la configuración de la vida social del presente. Lo que se cuestiona, a nivel general, es que ello no se haga, en un sistema elaborado y bien ponderado, por el legisla-

57 Requisito este último que algunas voces consideran matizable en situaciones de insolvencia, de modo que esta circunstancia no haya de resultar por sí sola impeditiva: CAmpos Daroca, J.M., La extinción de la relación de servicio de los empleados públicos. Personal funcionario y laboral, Bosch, Barcelona, 2013, p. 85.

58 Esta situación es todavía más plausible con la ampliación de los plazos de cancelación operada por la L.O. 1/2015 que, por ejemplo, fijó en diez años los de las inhabilitaciones absolutas y de las especiales superiores a cinco (art. 136 e) en relación con el art. 33.2 c) $\mathrm{y} d$ ) $\mathrm{CP}$ ). 
dor, sino que lo acabe haciendo, sin la taxatividad necesaria, el aplicador del derecho con clasificaciones propias y coyunturales. Se cuestiona pues, solo, la ligereza con la que el legislador asigna de entrada, en un número excesivo de casos, ese efecto permanente y la pereza con la que se desentiende después de todo el proceso de ejecución, dejando en manos de la Administración su reversión; y se propugna, a cambio, un sistema más cuidadoso de selección en origen combinado con una elaboración detenida de criterios legales, como pueda ser la revisión asociada al trascurso de determinados periodos de tiempo, bajo control judicial de la ejecución de la pena privativa de derechos. Se cuestiona también, en fin, y descendiendo al punto más concreto en el que estamos, que factores que ya han sido tenidos en cuenta por el legislador para fijar la gravedad abstracta del hecho y después por el juzgador penal para adecuarla al caso concreto, factores que ya se encuentran, por tanto, reflejados en la pena impuesta, puedan ser de nuevo considerados por la Administración para prolongar sus efectos. No sin cierto asombro se asiste, en este sentido, a expedientes de rehabilitación en los que se valoran elementos sustantivos ya valorados, como puede ser la naturaleza dolosa del delito cometido (en sentido desfavorable ${ }^{59}$ ), o se tienen arbitrariamente en cuenta circunstancias procesales que ya tuvieron asimismo su oportuno reflejo en la pena, como el hecho de que se dictase sentencia de conformidad en el asunto en cuestión ${ }^{60}$, si es que no se asiste a procedimientos en los que la argumentación consiste sencillamente en reenjuiciar la gravedad de los hechos o en parafrasear las propias valoraciones judiciales que condujeron al pronunciamiento condenatorio.

De similar mal (doble valoración) adolece, a mi juicio, la toma en consideración a efectos rehabilitadores de la relación del hecho con el cargo funcionarial, puesto que tal circunstancia pudo valorarse (rectius, debió ser valorada) a la hora de asociar al hecho la privación definitiva de ese cargo. En principio, en efecto, en las inhabilitaciones previstas como principales debería ser el propio legislador quien hubiese considerado ya el carácter público del autor a nivel de la individualización legal de la pena, mientras que en el funcionamiento de las mismas como accesorias esa conexión vendría establecida, motivadamente, a nivel de la individualización judicial. En tal contexto ideal, resulta obvio que si se inhabilita al reo por abusar del cargo se valora dos veces lo mismo si se le deniega después la rehabilitación por haber abusado de él. Lo que ocurre en este caso - en cierto paralelismo con el anterior- es que de nuevo la labor legislativa previa se revela aquí defectuosa, insuficiente, y aunque la legitimación correcta de la pena de inhabilitación exige asociarla a la utilización desviada de la función pública, la realidad es que

59 Así, p.e., STS, Sala Contencioso-Administrativo (Secc. 7. a) de 12 de junio de 2014 (RJ 2014/3944; Roj: 2413/2014). Valora favorablemente el carácter imprudente de los hechos la STS 1601/2016, de 29 de junio (RJ 2016/4176).

60 Vg., STS 1021/2017, de 10 de julio (RJ 2017/3241). 
en nuestro Derecho eso aún no ha sucedido de forma plena, existiendo incluso supuestos, como las inhabilitaciones absolutas accesorias en función de la duración de la pena (y no de la conexión con el cargo), en que ello no se produce en modo alguno. Ese déficit en la selección de las conductas hace que este criterio de la "relación del hecho delictivo con el desempeño del cargo funcionarial» (art. 6.2.c) encuentre un nicho de actuación legítimo en nuestro ordenamiento que no debería producirse en un sistema bien ponderado de inhabilitación. Pero ello debe considerarse expresión de una deficiencia del sistema antes que de la bondad del criterio de rehabilitación en sí. Lamentablemente, y de todas formas, no es en este puntual sentido, esto es, en el de intentar evitar valorar dos veces lo mismo (para imponer la pena y para no rehabilitarla) en el que se utiliza comúnmente el criterio de referencia (a la espera de la deseable modificación legislativa), sino que la referencia al hecho de que el delito causante de la condena no fue ajeno al quehacer funcionarial se puede leer con profusión en nuestras sentencias para reforzar -o incluso fundamentar- la resolución denegatoria ${ }^{61}$.

5. Sí admiten entre sus posibles entendimientos, en cambio, una interpretación acorde con el fundamento de la rehabilitación aquí defendido los criterios contenidos en las letras b), e) y f) del art. 6.2. El primero alude al «daño y perjuicio para el servicio público derivado de la comisión del delito». Conforme al canon aquí propuesto, este criterio no debiera ser aplicado ciertamente para valorar aspectos que ya han sido tomados en consideración por otros cauces. No debiera así considerarse ni, por un lado, la indemnización del perjuicio al servicio público al que haya podido procederse por parte del condenado, puesto que la reparación pudo haber tenido su reflejo en la pena y en todo caso la satisfacción de las responsabilidades civiles constituye ya un presupuesto objetivo para proceder a la rehabilitación (art. 2.2 R.D. 2669/1998), como tampoco, por otro, debería considerarse el daño a la cosa pública que forma parte del propio contenido de injusto del delito que se cometió, pues ello supondría emplear este criterio como reflejo de la propia gravedad de los

61 Por ejemplo, la STS Sala Cont-Adm., Secc. 7. ${ }^{\text {, }}$, de 12 junio 2014 (RJ 2014/3944; Roj: 2413/2014), señala sin ningún pudor, en relación con un delito de torturas, que «en cuanto al criterio orientador referido a la relación del hecho delictivo con el desempeño del cargo funcionarial, cabe señalar que los hechos delictivos para los que fue condenado estaban directamente relacionados con el desempeño de su cargo como funcionario, ya que fue precisamente dicha condición y el incumplimiento de las obligaciones que ello conllevaba lo que determinó que se propiciara la realización de los hechos delictivos y que fueran constitutivos del tipo penal de torturas de los artículos 174, apartados 1 y 2 , y 177, del Código penal aplicable, de acuerdo con la sentencia condenatoria. La aplicación de dichos preceptos recoge como elemento característico la condición de funcionario público, de modo que es en tal condición en la que se produce la comisión del delito». Los ejemplos pueden multiplicarse sin dificultad: funcionario de Correos que se apropia de giros postales (STS de 14 de octubre de 2010 -RJ 2010/7257; Roj: 5224/2010—), detención ilegal por parte de funcionario de policía (STS de 26 de abril de 2016 - RJ 2016/2010; Roj: 2080/2010-), etc. 
hechos, baremo que ya se ha censurado anteriormente por haber tenido su repercusión en la propia pena impuesta. Sin embargo, sí resulta acorde con el entendimiento aquí expuesto la valoración del daño y perjuicio como expresión de la desacreditación del servicio de que se trate en el caso concreto, con incidencia en la confianza en el mismo y perjudicando en forma destacada su imagen, lo que constituye un valor instrumental necesario para que aquél pueda servir con objetividad los intereses generales. En este sentido, resultan aceptables indicadores que en absoluto podrían fundamentar la desvaloración del hecho, como pueden ser la alarma social generada por el episodio en cuestión o la difusión que este haya obtenido, variables que, nótese, no son imputables al autor y por tanto deben mantenerse alejadas de la definición de la pena justa, pero que sí pueden afectar, en cambio, al mantenimiento de la necesidad de pena, cuestión que como se dijo no tiene ya por qué resultar igualitaria y que puede depender, incluso, del azar. Así, las SSTS de 16 de septiembre de 2013 o la más reciente de 10 de julio de 2017, por ejemplo, pudieron conceder legítimamente la rehabilitación, aun tratándose de penas de inhabilitación absoluta, al valorar la primera la falta de constancia de que la conducta hubiera tenido «una difusión más allá de la que comporta necesariamente todo proceso penal ${ }^{62}$, o valorando el hecho de que no se dedujese de los hechos «trascendencia pública con alarma social alguna ${ }^{63}$, la segunda. Sin incongruencia por lo que se refiere a este concreto parámetro, pudo también por ejemplo la STS de 14 de octubre de 2010 denegar la rehabilitación respecto de pena de menos enjundia (un año de inhabilitación especial) al considerar especialmente relevante en el caso concreto el perjuicio ocasionado a la imagen del servicio de Correos, perjuicio que, a juicio de esta resolución, «no desaparece porque el autor de ese comportamiento reparase posteriormente el daño causado, ya que esa actitud no elimina la gravedad de los hechos ni evita la pérdida de confianza de los usuarios del servicio público» ${ }^{64}$. Existe, por tanto, una vertiente de la dañosidad y del perjuicio que ocasiona el hecho que resulta inherente a la figura de que se trate, y de la que debe hacerse abs-

62 En un supuesto de malversación en el que el condenado, a la sazón destinado como agente ejecutivo de la Unidad de Recaudación Ejecutiva n. ${ }^{\circ} 2$ de los Cristianos, Santa Cruz de Tenerife, se había apropiado en tres ocasiones a lo largo del año 1992 de diversas cantidades que había recaudado a distintas empresas, ascendiendo el montante total de lo que dejó de ingresar a 656.214 pesetas, cantidad que el condenado había devuelto a lo largo del año 1993.

63 Respecto, en este caso, de la emisión de cinco cheques por importe de unos 7.000 euros, más allá de que fuesen rechazadas las facturas por la Intervención Provincial.

${ }^{64}$ En este supuesto, el cartero condenado se había apropiado de diversos giros postales por valor de 10.495 euros, falsificando la firma del destinatario. La sentencia tuvo especialmente en cuenta el informe negativo del Subdirector de Gestión de Personal de la Sociedad Estatal Correos y Telégrafos, que incidía en la afectación de la imagen del servicio. En otras ocasiones, la afectación de la confianza de los ciudadanos en la función pública parece valorarse con carácter general, en función de la naturaleza del delito (así, p.e., STS de 12 de junio de 2014, torturas menos graves -RJ 2014/3944; Roj: 2413/2014—). 
tracción a efectos de rehabilitación al haber tenido su reflejo en la pena asignada al mismo (la malversación, p. e., prevé incluso tratamientos agravados cuando se hubiera causado un grave daño o entorpecimiento del servicio, o cuando se superan ciertas cantidades, atenuando la responsabilidad por debajo de otras); pero sí debe valorarse el impacto en la confianza colectiva en el servicio, lo que si bien es verdad que puede ir en consonancia con la propia gravedad del hecho, es cuestión que discurre por sus propios cauces, más atenta a circunstancias externas y coyunturales, como la propia publicidad que haya obtenido - y mantenido en el tiempo- el delito en cuestión.

También «el tiempo transcurrido desde la comisión del delito» (letra $e$ ) puede tener una interpretación plausible en la clave aquí propugnada, debiendo reputarse un criterio válido a estos efectos, ya que es indiscutible que el tiempo difumina el impacto social del hecho, que llega a resultar irrelevante para la configuración de la vida social del presente. Únicamente cabe propugnar aquí un mayor esfuerzo para objetivar este criterio, exigiendo el establecimiento de plazos concretos que, al menos, acoten la subjetividad con la que actualmente se aplica, y que deberían armonizarse (no equipararse) con los requeridos por otras instituciones que manejan el parámetro temporal, como la prescripción de la pena o la cancelación de antecedentes penales. Así, por ejemplo, puede resultar en principio razonable que este factor de la rehabilitación sea considerado en sentido favorable aunque el periodo transcurrido resulte inferior al que correspondería para decretar la prescripción de la pena, puesto que dicha pena se ha cumplido; pero no será fácilmente entendible que se exija para puntuar, por así decir, por este concepto, que además del cumplimiento se exija un periodo superior al de la prescripción que correspondería de no haberse cumplido ${ }^{65}$.

Asimismo, en fin, debe reconocerse validez al criterio consistente en los «informes de los titulares de los órganos administrativos en los que el funcionario prestó sus servicios» (letra $f$ ) siempre, claro está, que su contenido se centre en el aspecto aquí destacado como criterio rector, es decir, la incidencia en el servicio público que tendría la rehabilitación. Para ello, especial relevancia cabrá conferir al emitido por el titular del

${ }^{65}$ La STS de 12 de junio de 2014 (RJ 2014/3944), sin embargo, consideró insuficiente el periodo de quince años, coincidente con el de prescripción; la jurisdicción contenciosa argumentó únicamente para ello que «el periodo de tiempo transcurrido no resulta significativo en razón de la gravedad de los hechos cometidos y que se reflejó en la pena impuesta» (Fdto. Jco. 3. ${ }^{\circ}$, sic.). Sí valoró, p. e., positivamente el transcurso de dieciséis años (plazo de prescripción de diez) la STSJ Cataluña n. ${ }^{\circ}$ 93/2014, de 4 de febrero (RJCA 2014/384). Se indicaba en ella que: «La resolución no contiene referencia al transcurso de más de 16 años desde la realización de los hechos con trascendencia penal. Este es un dato suficientemente importante como para determinar que ese dilatado espacio en el tiempo conlleva una distancia más que importante y que supone una ruptura vital con lo que aconteció en el año 1995». 
organismo administrativo que constituyó el último destino del condenado (STS de 16 de septiembre de 2013).

En definitiva, en un sistema bien ponderado de inhabilitación/ rehabilitación, esta última debiera atender únicamente a circunstancias sobrevenidas, posteriores a la condena (no coetáneas, como la gravedad del propio hecho, pues resulta inapropiado volver a valorar circunstancias ya consideradas en la imposición de la pena y que no excluyeron que aquélla fuese de inhabilitación). Tales circunstancias, de carácter excepcional, debieran evidenciar en relación con la confianza social en el servicio público atacado una reducción, en el caso concreto, del impacto que en abstracto se le supuso a la reincorporación por parte del legislador a la hora de asignar como pena al hecho una privación definitiva de la condición pública. Entre ellos podrían tener cabida tanto, de un lado, aspectos dependientes del propio condenado, incentivando así un efecto preventivo-especial hacia la reinserción (la jurisdicción contenciosa ha valorado, p. e., la obtención del perdón del perjudicado por el delito tras una carta de arrepentimiento y petición de disculpas presentada por aquél -STS de 29 de junio de 2016- o la constancia en el expediente de un escrito favorable firmado por un elevado número de compañeros -STS de 14 de julio de 2004-), como, de otro lado, acontecimientos del todo ajenos al condenado, como pudiera ser una modificación legal favorable sobrevenida que implicase un cambio en la valoración social del propio hecho que motivó la condena - y de su pena- (STS de 16 de septiembre de 2013), que lógicamente no podría ser aplicada retroactivamente tras el cumplimiento. También aspectos hoy no considerados, como el desempeño de funciones sin incidencias en el mismo sector de actividad (más aún si realizadas en el propio ámbito de la Administración ${ }^{66}$ ), podrían encontrar su espacio en una futura regulación de este instituto.

En todo caso, y para finalizar, conviene recordar que en la regulación actual el criterio del impacto de la reincorporación en la credibilidad del servicio público afectado no es el que se recoge exactamente en la cláusula de cierre del art. 6.2 R.D. 2669/1998 (letra g), con la que se precisa el que debe ser el criterio general supletorio. Su alusión, por una parte, a la "gravedad objetiva del delito cometido" ha sido ya suficientemente comentada (y combatida); sí podrá interpretarse en el sentido aquí propuesto, en cambio, la referencia también contenida a la «incidencia sobre la futura ocupación de un puesto de funcionario público", si bien evitando en todo caso que a través de ella se cuele entre las potestades administrativas una finalidad de evaluación de las capacidades del reo que ha de reputarse extraña a la rehabilitación ${ }^{67}$.

${ }^{66} C f r$. STSJ Cataluña n. ${ }^{\circ}$ 93/2014, de 4 de febrero, Fdto. Jco. Quinto y STS (Sala Cont.Admvo, Secc. 7. ${ }^{a}$ ) de 1 de julio de 2015, casando la anterior.

67 Campos Daroca, J.M., op. cit., p. 88. 